\title{
On the photometric error calibration for the 'differential light curves' of point-like Active Galactic Nuclei
}

\author{
Arti Goyal, ${ }^{1,2 *}$ Mukul Mhaskey, ${ }^{3}$ Gopal-Krishna, ${ }^{1,2}$ Paul J. Wiita, ${ }^{4}$ \\ C. S. Stalin ${ }^{5}$ and Ram Sagar, ${ }^{6}$ \\ ${ }^{1}$ National Centre for Radio Astrophysics (NCRA), TIFR, Pune 411 007, India. \\ 2 Inter University Centre for Astronomy and Astrophyics (IUCAA), Post Bag 4 Ganeshkhind, Pune University Campus, \\ ${ }^{3}$ Department of Physics, Pune University, Pune 411 007, India. \\ ${ }^{4}$ Department of Physics, The College of New Jersey, PO Box 7718, Ewing, NJ 08628-0718, USA. \\ ${ }^{5}$ Indian Institute of Astrophysics (IIA) Bangalore 560 034, India. \\ ${ }^{6}$ Aryabhatta Research Institute of Observational Sciences (ARIES), Manora Peak, Naini Tal 263 129, India.
}

Received xxx; accepted xxx

\begin{abstract}
It is important to quantify the underestimation of rms photometric errors returned by the commonly used APPHOT algorithm in the IRAF software, in the context of differential photometry of pointlike AGN, because of the crucial role it plays in evaluating their variability properties. Published values of the underestimation factor, $\eta$, using several different telescopes, lie in the range $1.3-1.75$. The present study aims to revisit this question by employing an exceptionally large data set of 262 differential light curves (DLCs) derived from 262 pairs of non-varying stars monitored under our ARIES AGN monitoring program for characterizing the intra-night optical variability (INOV) of prominent AGN classes. The bulk of these data were taken with the 1-m Sampurnanad Telescope (ST). We find $\eta=1.54 \pm 0.05$ which is close to our recently reported value of $\eta=1.5$. Moreover, this consistency holds at least up to a brightness mismatch of 1.5 mag between the paired stars. From this we infer that a magnitude difference of at least up to 1.5 mag between a point-like AGN and comparison star(s) monitored simultaneously is within the same CCD chip acceptable, as it should not lead to spurious claims of INOV.
\end{abstract}

Key words: Photometry: optical - photometry: Methods: data analysis - Optical: variability-AGN 


\section{Introduction}

Observations of intensity variations at different wavelengths constitute a highly effective probe of the physics of active galactic nuclei (AGN). In the optical domain, numerous such studies have been carried out, covering time scales down to hours and even minutes, sometimes coordinated with monitoring in other wavebands (e.g., Miller, Carini, \& Goodrich 1989; Wagner \& Witzel 1995; Jang \& Miller 1995, 1997; Romero, Cellone, \& Combi 1999; Romero et al. 2002; GopalKrishna, Sagar, \& Wiita 1993a; Gopal-Krishna, Wiita, \& Altieri 1993b; GopalKrishna, Sagar, \& Wiita 1995; Gopal-Krishna et al. 2000, 2003, 2011; Sagar, Gopal-Krishna, \& Wiita 1996; Sagar et al. 2004; Carini et al. 1991, 1992, 2007; Carini, Miller, \& Goodrich 1990; Carini \& Miller 1992; Carini, Noble, \& Miller 1998, 2003; Stalin et al.2004a b, 2005; Noble et al. 1997; Goyal et al. 2007, 2009, 2010, 2012; Gupta \& Joshi 2005; Gupta \& Yuan 2009; de Diego et al. 1998; Ramírez et al. 2009; Joshi et al. 2011; Gupta et al. 2008a b, 2012; Rani et al. 2010a b, 2011; Gaur et al. 2010, 2012). Since 1990, most observations of intranight optical variability (INOV) have been made using CCD detectors, which allow simultaneous recording of a number of stars within the same chip. Not only are some of these simultaneously monitored stars used for measuring any variations in the seeing disk during the course of the monitoring session, but, more importantly, they are used as non-varying standards relative to which the light curve of the target AGN can be drawn. Such 'differential light curves' (DLCs) are also drawn for the candidate 'comparison stars' themselves and used to check for the presence of INOV of those stars, in which case they are disqualified as comparison stars (e.g., Miller \& Wiita 1991; Stalin et al. 2004b; Wiita 2006). A key advantage of using DLCs is that the effects of any fluctuations in the atmospheric attenuation and even in the seeing disk are mostly canceled out, and this way the variability detection threshold is pushed down enormously (e.g., Howell \& Jacoby 1986; Miller, Carini, \& Goodrich 1989; Gilliland et al. 1993; Howell et al. 2005). Thus, intra-night optical variability (INOV) with amplitudes as low as 1 to 2 per cent can be routinely detected using 1-metre class telescopes. (e.g., see Goyal et al.|2012 and references therein). Since 1998, a large body of such sensitive observations has been accumulated, in a fairly uniform manner, using the 104-cm Sampurnanand telescope of ARIES in Nainital (India) (Stalin et al. 2004a b, 2005; Gupta et al. 2008a b, 2012; Gopal-Krishna et al. 2003, 2011; Goyal et al. 2007, 2009, 2010, 2012 ). Usually, the targets monitored in these studies are optically luminous and relatively bright point-like AGN, namely, quasars (both radio-loud and radio-quiet) and BL Lacs, in the magnitude range $m_{v}=15-17$ mag.

A number of statistical tests have been employed in the literature for detecting the presence of variability in DLCs. Until recently, the most popular test has been the, so called, $C$-test (Jang \& Miller 1997; Romero et al. 1999). Basically, this involves computation of a factor ' $\mathrm{C}$ ' for a given DLC of a target object, where $\mathrm{C}$ is the ratio of the standard deviation of the AGN light curve to the standard deviation of the 
comparison star-star light curve, i.e.,

$$
C=\frac{\sigma_{t-s}}{\sigma_{s-s}}=\frac{\sigma_{t-s}}{\left\langle\sigma_{t-s}\right\rangle}
$$

where $\sigma_{t-s}$ is the standard deviation of the 'target-star' DLC, and $\left\langle\sigma_{t-s}\right\rangle$ is the mean of the (formal) rms errors of the individual data points in the 'target-star' DLC.

This ratio ' $\mathrm{C}$ ' has been taken to have a Gaussian (normal) distribution (e.g., Jang \& Miller 1997, Romero et al. 1999). Thus, an AGN DLC found to have ' $\mathrm{C}$ ' greater than 2.576 (corresponding to significance level, $\alpha=0.01$ ) is declared to be 'variable'. Similarly, an AGN DLC having computed 'C' value greater than 1.950 and less than 2.576 (corresponding to $\alpha=0.05$ ) is termed as 'probable variable'. However, recently, de Diego (2010) has questioned the validity of this test on the ground that $\mathrm{C}$-statistics does not have a normal distribution and the two tailed p-values of normal distribution should not be used as a statistical indicator of INOV at a given $\alpha$ (variable vs. non-variable). The argument is as follows :

(a) The $\mathrm{C}$-statistic is always positive, making it a one-sided comparison, unlike the normal Gaussian distribution which is two-sided comparison.

(b) For a test statistic to have a standard normal distribution, the expected value is distributed around 0 while in case of ' $\mathrm{C}$ ' statistic it is distributed around 1 when $\sigma_{t-s}=\sigma_{s-s}$ is satisfied.

(c) One cannot compare two standard deviations using the normal distribution as they are not lineal statistical operators.

Thus, de Diego (2010) has argued in favour of $F$-test which relies on the computation of $F$-factor, being the ratio of two variances, as follows (see also, Villforth, Koekemoer, \& Grogin 2010):

$$
F=\frac{\text { Var }_{\text {observed }}}{\text { Var }_{\text {expected }}}=\frac{\operatorname{Var}_{t-s}}{\operatorname{Var}_{s-s}}=\frac{\operatorname{Var}_{t-s}}{\left\langle\sigma_{t-s}^{2}\right\rangle}
$$

where $\operatorname{Var}_{t-s}$ is the variance of the 'target-star' DLC, and $\left\langle\sigma_{t-s}^{2}\right\rangle$, is the mean of the squares of the (formal) rms errors of the individual data points in the 'target-star' DLC.

Clearly, both the $C$-test and the $F$-test require a precise estimate of the rms error $(\sigma)$ associated with individual data points, which is usually determined using the APPHOT routine in the IRAF ${ }^{1}$ software. Many years ago, it was pointed out that the $\sigma$ returned by this algorithm is systematically too low by a factor, $\eta$, for which a value of 1.75 was estimated using the DLCs derived for pairs of steady stars (Gopal-Krishna et al. 1995). This inference $(\eta \neq 1)$ has been borne out in several independent studies from atleast 4 different observatories and the derived values of this parameter range between 1.3 and 1.75 (Gopal-Krishna et al. 1995, Garcia et al. 1999; Bachev et al.|2005; Stalin et al. 2004b; Goyal et al.2007). The

\footnotetext{
${ }^{1}$ Image Reduction and Analysis Facility (http://iraf.noao.edu/)
} 
most recent attempt to determine $\eta$ used DLCs for 73 pairs of steady stars and a best-fit value of $\eta=1.5$ was obtained (Goyal et al. 2012). Clearly, a neglect of $\eta$ factor (i.e., setting $\eta=1$ ) might often lead to spurious claims of INOV (above a preset statistical significance threshold). It is therefore important to achieve a greater precision in the determination of $\eta$, by avoiding the use of any photometric data that fall within a parameter space that is more prone to introducing larger uncertainty in the $\eta$ determination.

A prime candidate for a part of this 'undesirable' parameter space is the mismatch between the brightness of the chosen steady comparison stars which are paired to derive the DLCs which are collectively used for $\eta$ determination. The mismatch can be represented by $\Delta m_{s}=m_{s 1}-m_{s 2}$. The purpose of the present study is to identify the 'safe' parameter space for $\Delta m_{s}$, outside which a significant distortion of the $\eta$ estimate can occur. This has important implications for the INOV search since several claims of large INOV of AGN have been questioned because of a large mismatches between their brightnesses and those of the comparison stars used for deriving the differential light curves (e.g., Cellone et al.2007).

\section{The sample of intra-night optical DLCs}

Using the 1-m Sampurnanand telescope (ST) of ARIES, a long-term programme was launched in 1998, for characterizing the INOV properties of important AGN classes. Results of this ongoing study have been reported in a series of publications and in the Ph.D. theses of C. S. Stalin (2003) and Arti Goyal (2010) (Goyal et al. 2012 and references therein; Stalin et al. 2005 and references therein). Optical intra-night monitoring data from other optical observatories in India, such as the 2-m Himalayan Chandra Telescope (HCT) and the 2.4m Vainu Bappu Telescope (VBT) of IIA, the $1.2 \mathrm{~m}$ telescope at the Gurushikhar observatory of PRL and the 2-m IUCAA Girawali Observatory (IGO) telescope of IUCAA were also obtained to augment the data taken with the 1-m ST. Nearly always, just one target AGN was monitored on a given night.

The above intra-night monitoring program has covered 22 radio-quiet quasars (RQQs), 10 radio-intermediate quasars (RIQs), 9 radio lobe-dominated quasars (LDQs), 11 radio core-dominated quasars showing high optical polarization (HPCDQs) and 12 showing low optical polarization (LPCDQs), as well as $13 \mathrm{TeV}$ detected BL Lac objects. Sources in the various classes were chosen from the catalog of VéronCetty \& Véron (2001) and its subsequent releases. All the sources lie at $z>0.14$ and have a listed $m_{B}<18 \mathrm{mag}$, which allows enough signal-to-noise ratio (SNR) in a typical exposure time of $\sim 10$ minutes. Each source was monitored for a minimum duration of $\sim 4$ hours. These CCD monitoring observations, aided by a careful and uniform data analysis procedure, have routinely allowed INOV detection with amplitude $(\psi)$ as low as 1 - 2 per cent. The present sample consists of 262 such intra-night observations obtained from the entire data set from our ARIES 
AGN INOV programme.

\section{Observations and data analysis}

The observations were made mostly in the $R$ filter and occasionally in the $V$ filter. The exposure time was typically between 10 to 20 minutes for the ARIES and Gurushikar observations and ranged between 3 to 6 minutes for the observations from VBT, IAO and IGO, depending on the brightness of the source, the phase of the moon and the sky transparency on that night. The field positioning was adjusted so as to also have within the CCD frame at least 2-3 comparison stars. For all the telescopes, bias frames were taken intermittently, and twilight sky flats were also obtained.

The pre-processing of the images (bias subtraction, flat-fielding and cosmic-ray removal) was done by applying the standard procedures in the IRAF and MIDAS ${ }^{2}$ software packages. The instrumental magnitudes of the target AGN (all point-like) and the stars in the image frames were determined by aperture photometry, using APPHOT. The magnitude of the target AGN was measured relative to a few apparently steady comparison stars present on the same CCD frame. In this way DLCs for each AGN were derived relative to 2-3 comparison stars designated as S1, S2, S3.

These comparison stars mostly lie within about 1.5 magnitude of the target AGN, this being an important criterion for minimizing the possibility of spurious INOV detection (e.g., Cellone et al. 2007). Spurious variability on account of different second-order extinction coefficients for the AGN and their comparison stars is a possible problem if the colours of the objects are different. Although the $B-R$ colors of the AGN and the comparison stars used in our study often differ significantly, it was shown by Carini et al. (1992) and Stalin et al. (2004b) that even though their photons travel through varying airmass during the course of monitoring, this has a negligible effect on DLCs. For each night, an optimum aperture radius for photometry was chosen by minimizing the dispersions in the star-star DLCs, that were found using different aperture radii, starting from the median seeing (FWHM) value on that night to 4 times that value (Fig. 11). For very small aperture radii, the scatter will be large due to improper photon counting statistics, as the total photon count from the source will be small. On the other hand, at very large aperture radii, the scatter will increase as the on-source measurement will be affected by the emission from the sky background (Howell 1989). At intermediate aperture radii, a minimum will occur as shown in Fig. 1. We selected the appropriate aperture for each night as the one that provided the minimum dispersion for the DLC found among all pairs of the comparison stars, as the same stars would be used to produce DLCs

${ }^{2}$ Munich Image and Data Analysis System (http://www.eso.org/sci/data-
processing/software/esomidas/)




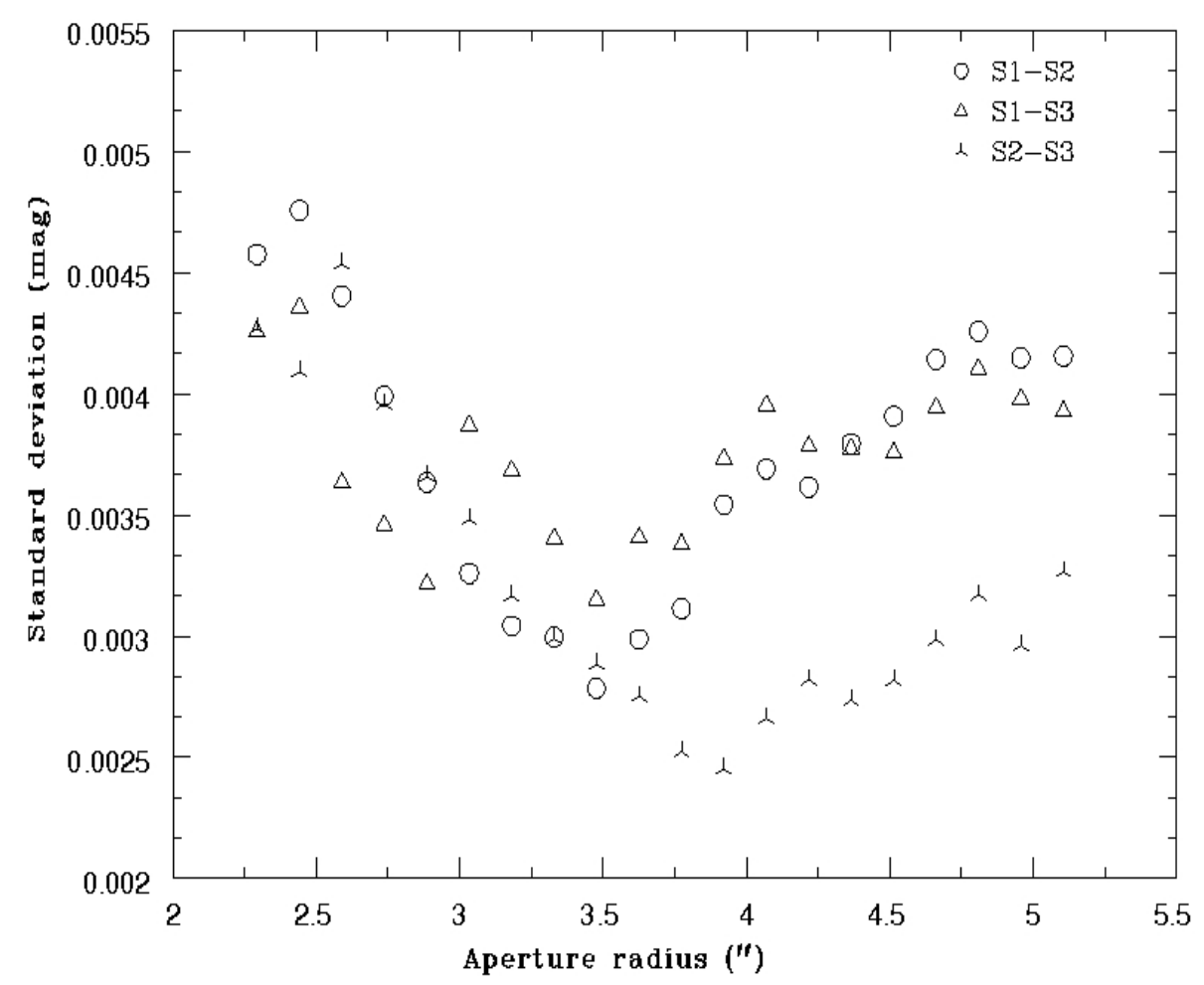

Figure 1 The rms of the DLCs derived for a pair of (steady) comparison stars used for the target quasar $\mathbf{J} 2203+3145$, versus photometric aperture radius, monitored on 15-Sep-2007. The minimum in standard deviation on that night is seen to occur for an aperture radius $\simeq 3.8$ arcsec.

against the target quasars to check for their INOV. Thus, using the aperture which provides minimum dispersion will set a threshold for INOV detection on that night (e.g., Stalin et al. 2004b). Typically, the selected aperture radius was $\sim 4^{\prime \prime}$ and the seeing was $\sim 2^{\prime \prime}$.

\section{Determination of $\eta$}

As mentioned in Sect. 1, the photometric errors returned by APPHOT are significantly underestimated. In this work, we make a fresh attempt to determine $\eta$ using our enlarged dataset of 262 DLCs from our ARIES AGN monitoring program (see Goyal et al. 2012; Sect. 2). Out of the 3 star-star DLCs available for each night (us- 
ing the 3 comparison stars monitored), we first selected the steadiest (one having minimum variance) star-star DLC. Thus, for our entire dataset we have got 262 'steady' DLCs, whose 524 stars appear to have not varied on the corresponding nights. For each selected DLC, with $N_{p}$ points, we then computed $\chi^{2}$ corresponding to its degree of freedom, $v=N_{p}-1$, which is given as;

$$
\chi^{2}=\sum_{i=1}^{N_{p}-1} \frac{1}{\sigma_{i}^{2}}\left(\Delta m_{i}-\langle\Delta m\rangle\right)^{2}
$$

where the expected value $\langle\Delta m\rangle$ is the sample mean of the DLC. $N_{p}$ is the number of data points in the lightcurve, $\Delta m_{i}$ is the differential magnitude of the $i^{t h}$ data point in the lightcurve and $\sigma_{i}$ is the rms measurement error associated with each $\Delta m_{i}$.

To compute $\eta$, we use

$$
v=\sum_{i=1}^{N_{p}-1} \frac{1}{\eta^{2} \sigma_{i}^{2}}\left(\Delta m_{i}-\langle\Delta m\rangle\right)^{2}
$$

where the degree of freedom $v$ is also the expected $\left\langle\chi^{2}\right\rangle$ value for a pair of nonvariable stars. The simplest approach is to use regression analysis given by

$$
\chi^{2}=\eta^{2} v+\epsilon
$$

where $\epsilon$ is the residual associated with each pair of $\chi^{2}$ and $v$. However, we do not know that residuals are Gaussian distributed, or are homogeneous with respect to the values of independent variable, precluding a reliable least square fitting. As our regression analysis exhibit an "expected value - residual" we can transform the variables to stabilize the variance. The most common method is the Box-Cox set of tranformations (Box \& Cox 1964; Box, Hunter, \& Hunter 2005). In our case this involves using logrithms of the $\chi^{2}$ values to homogenize the variance of regression analysis and to maintain the linear relationship between the $\chi^{2}$ and $v$, we tranform $v$ to $\log (v)$. Then, we fix the slope to 1 in the regression analysis to obtain :

$$
\log \left(\left\langle\chi^{2}\right\rangle\right)=K+\log (v)
$$

where $\eta^{2}=10^{K}$. The error in $\eta^{2}$ is computed using Bevington \& Robinson (2003)

$$
\sigma_{\eta}^{2}=\eta^{2} \times\left(2.303 \times \sigma_{K}\right)^{2}
$$

where $\sigma_{K}$ is the error in $K$. Using these, we obtain $\eta=1.54 \pm 0.05$ for the entire set of 262 steady 'star-star' DLCs data listed in Table 1.

In Fig. 2, we plot for all 262 'steady' star-star DLCs, the computed $\chi^{2}$ values against the respective values of $v$. Accodingly, we adopt $\eta=1.54$, for scaling up the IRAF photometric rms errors (see Sect. 5). 


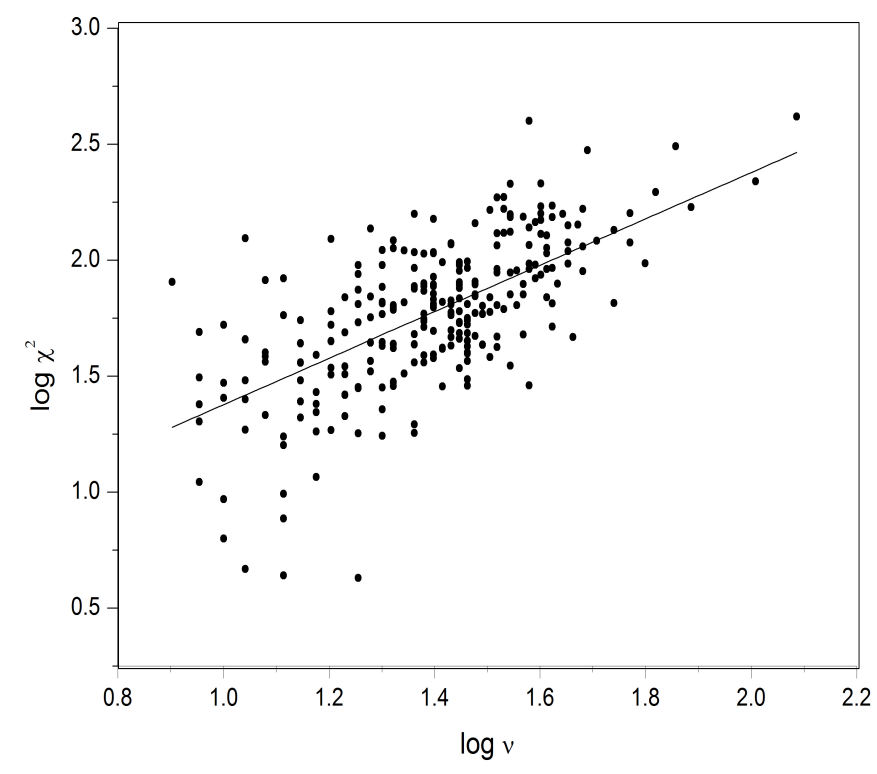

Figure 2 Plot of $\chi^{2}$ values against degrees of freedom, computed for our entire data set of 262 night. The solid line gives the slope fixed at 1 (see sect. 4).

As mentioned in Sect 1 , a principal goal of the present study is to check the dependence of $\eta$ on the brightness mismatch between the stars which are paired to derive the 'steady' star-star DLCs. For this, we divide our sample of 262 DLCs into subsamples corresponding to three intervals of the apparent magnitude difference $\left(\Delta m_{s}\right)$ between the star-pair (see column 7 of Table 1 ). These subsamples have $\Delta m_{s}$ in the ranges $0.00-0.40 \mathrm{mag}$ (148 DLCs), 0.40-0.80 mag (69 DLCs) and 0.80 to $1.50 \mathrm{mag}$ (39 DLCs). Out of the 262 DLCs star-star DLCs considered here, only 6 have $\Delta m_{s}>1.50 \mathrm{mag}$. The computed values of $\chi^{2}$ for the three subsamples are plotted in Fig. 3. We apply the regression analysis, as explained above, to compute the $\eta$ values for these subsamples. These values of $\eta$ are found to be $1.56 \pm 0.07$, $1.50 \pm 0.09$ and $1.56 \pm 0.13$ for the subsamples defined by $0.00<\Delta m_{s}<0.40,0.40$ $<\Delta m_{s}<0.80$ and $0.80<\Delta m_{s}<1.50$, respectively. We note that these values of $\eta$ are mutually consistent for the three magnitude bins. We thus conclude that the determination of $\eta$ is essentially independent of the brightness mismatch of at least up to 1.5 mag between the comparison stars used. 

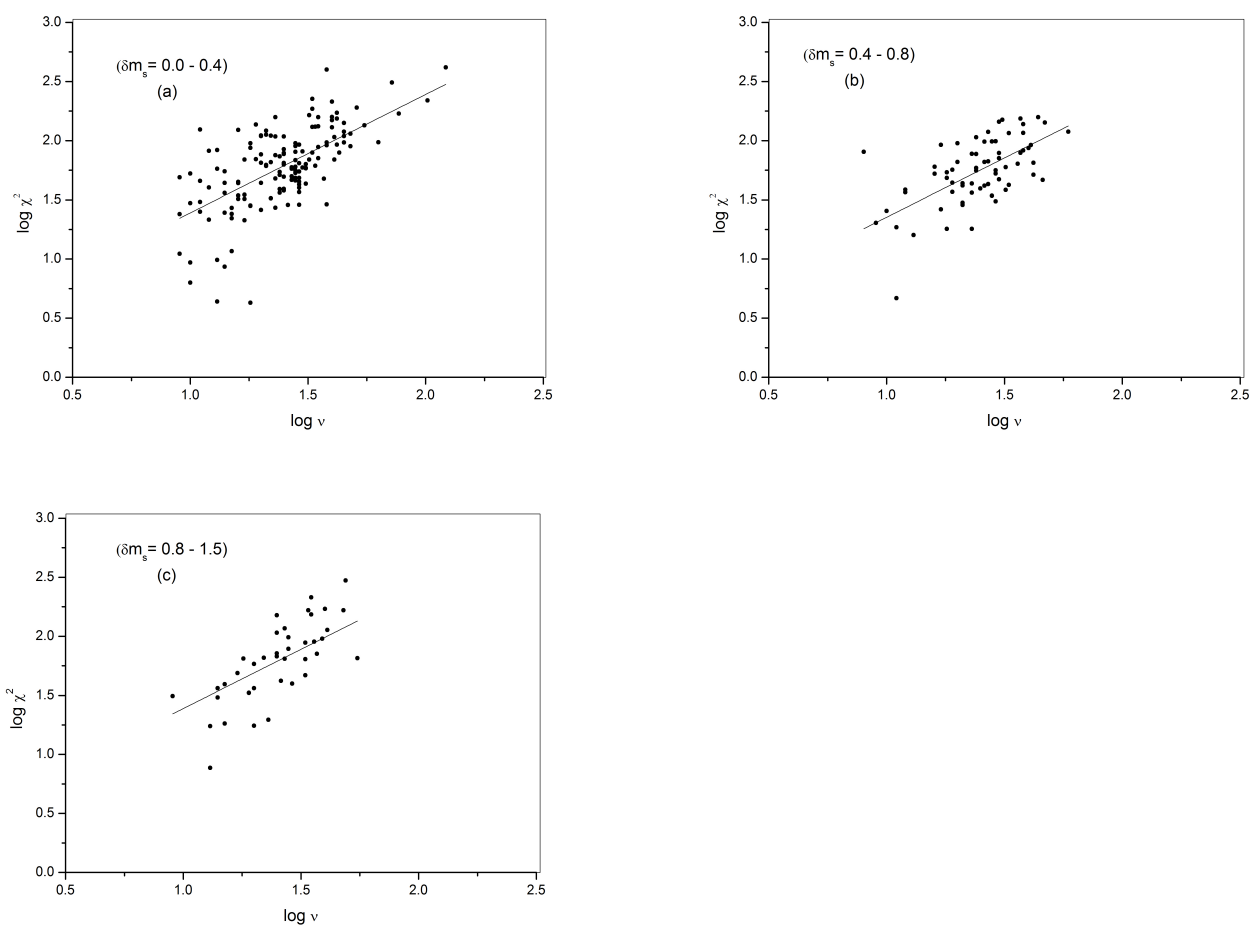

Figure 3 Plot of $\chi^{2}$ values against degrees of freedom, computed for the 3 ranges of apparent magnitude difference between the (steady) stars paired to derive the DLCs. (a) $\chi^{2}$ for the $\Delta m_{s}=0.00-0.40\left(148\right.$ DLCs); (b) $\chi^{2}$ for the $\Delta m_{s}=0.40-0.80$ (69 DLCs) and (c) $\chi^{2}$ for the $\Delta m_{s}=0.80-1.50$ (39 DLCs). The solid line shows slope of regression analysis fixed at 1 (see Sect.4).

\section{Discussion}

In order to counter-check these findings, we now subject our analysis to a sanity check (Table 1). For this we have computed the expected number of false positives ('Type 1 error') for our dataset of 262 DLCs. We have thus performed the $F-t e s t$ (Eq.2) on the 262 steady star-star DLCs after accounting for the photometric error underestimation factor (i.e., replacing the denominator with $\eta^{2} \sigma^{2}$ in Eq. 2). The expression for $F$ is given by $F_{v_{1}, \nu_{2}}^{\alpha}=\sigma_{1}^{2} / \sigma_{2}^{2}$ where $\sigma_{1}$ and $\sigma_{2}$ are the variances of the numerator and the denominator and the $v_{1}$ and $v_{2}$ are the corresponding degrees of freedom. In our analysis, we have simplified the $F$ expression to $F_{v}^{\alpha}$ as $v_{1}=$ $v_{2}=v$ is the degree of freedom for the 'star-star' DLC. In this way, the $F$-value was computed for each DLC and compared with the critical $F$-value. Recall that smaller the $\alpha$, the less likely is it to occur by chance. For the present study, we have used two values of significance level, $\alpha=0.01$ and 0.05 . Thus we claim a spurious INOV detection for a DLC, when the computed $F$ - value exceeds the critical 
$F$-value at $\alpha=0.01$. We thus assign a 'variable' designation (V) to it. We assign a 'probable variable' (PV) designation when the computed $F$ - value is found to be between the critical $F$ - values at $\alpha=0.01$ and 0.05 , otherwise 'non-variable' $(\mathrm{N})$ designation as assigned to the 'star-star' DLC.

Following this analysis, out of 262 steady 'star-star' DLCs, 6 DLCs were found to be of ' $\mathrm{V}$ ' type, while 12 were designated as 'PV' (Table 1). At $\alpha=0.01$ (i.e., $p>$ 0.99 ), we expect among the 262 'star-star' DLCs, $\sim 3$ DLCs to be falsely classified as 'V'. Similarly, at $\alpha=0.05$ (i.e., $p>0.95$ ), the expected number of false positives is $\sim 13$. We find that for our analysis, the observed number of false positive is 6 at $\alpha=0.01$ and 18 at 0.05 . Since the distribution of false positives (Type 1 errors) is binomial, we expect its actual number for a given test will be between 0 and 9 and in most cases between $3 \pm 2$ at $\alpha=0.01$. Similarly, at $\alpha=0.05$, the actual number of false positives will be between 2 and 24 and in most cases will be $13 \pm 4$. The good match between the observed and expected values of false positives validates our analysis procedure adopting $\eta=1.54$ as determined here.

Also, for our three subsamples defined in Sect. 4, we find the expected numbers of false postives for most cases will be $2 \pm 1$ ( 148 DLCs in the magnitude bin $0.0<$ $\left.\Delta m_{s}<0.4\right), 1 \pm 1$ (69 DLCs in the magnitude bin $0.4<\Delta m_{s}<0.8$ ) and $1 \pm 1$ (39 DLCs in the magnitude bin $0.8<\Delta m_{s}<1.5$ ) at $\alpha=0.01$. We find that the observed numbers for false positives are 4, 1 and 1. Similarly, at $\alpha=0.05$, expected numbers of false postives for most cases will be $7 \pm 3$ (148 DLCs in the magnitude bin $0.0<\Delta m_{s}<0.4$ ), $4 \pm 2$ (69 DLCs in the magnitude bin $0.4<$ $\left.\Delta m_{s}<0.8\right)$ and $2 \pm 2\left(39\right.$ DLCs in the magnitude bin $\left.0.8<\Delta m_{s}<1.5\right)$ at. We find that the observed numbers for false positives are 10, 3 and 5, respectively. This again shows a close match between the observed and expected values of false positives, validating the estimate of $\eta=1.54$ up to a magnitude mismatch of $\sim 1.5$ mag between the comparison star pairs.

The vast majority of the data analyzed here comes from ST and therefore our results strictly apply to those observations. The data from the HCT, IGO, GSO and VBT all seem consistent with the ST results, but each of these telescopes contributed measurements that are not numerous enough to perform useful separate analyses for these telescopes. Therefore we cannot yet determine whether the value of $\eta$ we have found is a fundamental feature of IRAF's APPHOT and thus universal, or somewhat dependent on the telescope and the instrument used. Over the next couple of years we anticipate obtaining comparably large data sets with a new ARIES $1.3 \mathrm{~m}$ telescope located at a different site near Nainital. We will perform a similar analysis of the values of $\eta$ for those additional data and that will lead us to a better grasp of the root of this error underestimation. We do, however, note that because the seeing varied substantially (from 0.7 to 3.5 arc sec) for the data we have employed here, the value of $\eta$ does seem to be fairly independent of this important aspect of the differential photometry process. 


\section{Summary}

In this study, we have determined the photometric error underestimation factor $\eta$ applicable to point-source aperture photometry carried out using the IRAF (APPHOT) software. For this we have used an unprecedentedly large set of 262 DLCs taken on 262 nights, about 85 per cent of which are taken with the 1-m telescope (ST) of ARIES. By subjecting this large database to a $\chi^{2}$ analysis we find that $\eta$ $=1.54 \pm 0.05$, which is consistent with the most recently published estimate of this important parameter, which was derived using a $\sim 4$ times smaller sample of DLCs than we have used here (see, Goyal et al. 2012). A sanity check, based on the computation of 'false positives' employing the $F$-test, was performed and it has validated the estimate of $\eta=1.54$.

We have further checked for any dependence of the $\eta$ factor on the apparent magnitude mismatch $\left(\Delta m_{s}\right)$ between the comparison stars paired (taking them to be steady, as inferred from inspection of their DLCs). For this we divided our sample of DLCs into three subsamples, characterized by $0.0<\Delta m_{s}<0.40$ (148 DLCs), $0.40<\Delta m_{s}<0.80$ (69) and $0.80<\Delta m_{s}<1.50$ (39 DLCs). For each subsample the sanity check again showed consistency with $\eta=1.54$. It is thus concluded that $\eta=1.54$ remains valid even when the magnitudes of the 'steady' stars paired to derive a DLC differ by as much as 1.5 mag. In other words, even a magnitude difference of up to 1.5-mag between the two stars paired to derive a DLC and $\eta$, should not result in a spurious claim of INOV for either of the two stars. As a corollary, it can be reasonably asserted that deriving DLCs of (point-like) AGN using a comparison star that is within about 1.5 magnitude of the AGN, should not lead to spurious claim of INOV for the AGN. However, this could well be the case for significantly larger magnitude mismatches, as argued by Cellone et al. (2007) in the context of some claims of dramatic INOV.

The present analysis is dominated by the $R$-band data taken using the ARIES 1-m telescope (ST). Therefore, the present conclusion strictly apply only to the $R$-band taken with this telescope. In the coming years, we plan to expand the present analysis to observation taken with the $1.3-\mathrm{m}$ Devasthal Optical Telescope (DOT) recently installed at a site well removed from that of the ST. 
Table 1. Summary of observations and derived variability status for the 'steady' star-star DLCs

\begin{tabular}{|c|c|c|c|c|c|c|c|c|c|c|c|c|}
\hline $\begin{array}{c}\text { AGN } \\
\text { name } \\
(1)\end{array}$ & $\begin{array}{l}\text { Obs. date } \\
\text { dd.mm.yy } \\
\text { (2) }\end{array}$ & $\begin{array}{l}\text { Tel. }{ }^{\text {II }} \\
\text { used } \\
\text { (3) }\end{array}$ & $\begin{array}{l}\text { Filter. } \\
\text { used } \\
(4)\end{array}$ & $\begin{array}{l}\text { Dur. } \\
\text { (hr) } \\
(5)\end{array}$ & $\begin{array}{l}N_{p} \\
\text { (6) }\end{array}$ & $\begin{array}{c}\Delta m_{s} \\
(\mathrm{mag}) \\
(7)\end{array}$ & $\begin{array}{c}\sigma \\
\left(10^{-2} \mathrm{mag}\right) \\
(8)\end{array}$ & $\begin{array}{c}\text { std dev. } \\
\left(10^{-2} \mathrm{mag}\right) \\
(9)\end{array}$ & $\begin{array}{l}\chi_{s}^{2} \\
(10)\end{array}$ & $\begin{array}{l}F_{S} \\
(11)\end{array}$ & $\begin{array}{l}\text { Status }^{\dagger} \\
\text { (12) }\end{array}$ & $\begin{array}{r}\operatorname{Ref}^{f} \\
\text { (13) }\end{array}$ \\
\hline \multicolumn{13}{|c|}{ Radio quiet quasars (RQQs)[22 sources; 68 DLCs] } \\
\hline $\mathrm{J} 0045+0410$ & 21.10 .98 & ST & $\mathrm{R}$ & 2.39 & 14 & 0.376 & 0.5 & 0.2 & 4.37 & 0.13 & $\mathrm{~N}$ & (a) \\
\hline $\mathrm{J} 0045+0410$ & 05.11 .98 & ST & $\mathrm{R}$ & 3.21 & 30 & 0.369 & 0.8 & 1.0 & 40.05 & 0.55 & $\mathrm{~N}$ & (a) \\
\hline J0045+0410 & 16.10 .04 & HCT & $\mathrm{R}$ & 6.04 & 25 & 1.859 & 0.1 & 0.2 & 79.36 & 1.24 & $\mathrm{~N}$ & (b) \\
\hline $\mathrm{J} 0103+0321$ & 05.11 .05 & HCT & $\mathrm{R}$ & 5.94 & 21 & 1.093 & 0.3 & 0.4 & 36.32 & 0.72 & $\mathrm{~N}$ & (b) \\
\hline J0103+0321 & 05.11 .05 & ST & $\mathrm{R}$ & 5.83 & 20 & 0.570 & 0.4 & 0.6 & 44.09 & 1.02 & $\mathrm{~N}$ & (b) \\
\hline J0239-0001 & 06.11 .05 & $\mathrm{HCT}$ & $\mathrm{R}$ & 6.42 & 19 & 0.779 & 0.1 & 0.2 & 53.90 & 1.26 & $\mathrm{~N}$ & (b) \\
\hline J0516-0027 & 10.12 .01 & ST & $\mathrm{R}$ & 5.77 & 23 & 0.160 & 0.3 & 0.3 & 32.50 & 0.56 & $\mathrm{~N}$ & (c) \\
\hline J0516-0027 & 19.12.01 & ST & $\mathrm{R}$ & 7.52 & 35 & 0.210 & 0.3 & 0.5 & 131.13 & 1.16 & $\mathrm{~N}$ & (c) \\
\hline J0516-0027 & 20.11 .03 & $\mathrm{HCT}$ & $\mathrm{R}$ & 7.28 & 39 & 0.264 & 0.1 & 0.2 & 96.37 & 1.07 & $\mathrm{~N}$ & (b) \\
\hline J0516-0027 & 18.11 .04 & ST & $\mathrm{R}$ & 6.29 & 34 & 0.282 & 0.1 & 0.2 & 79.19 & 1.01 & $\mathrm{~N}$ & (b) \\
\hline J0516-0027 & 16.12 .04 & HCT & $\mathrm{R}$ & 6.79 & 34 & 1.256 & 0.2 & 0.2 & 63.96 & 0.60 & $\mathrm{~N}$ & (b) \\
\hline $\mathrm{J} 0751+2919$ & 14.12 .98 & ST & $\mathrm{R}$ & 7.41 & 40 & 1.569 & 0.3 & 0.6 & 145.70 & 1.57 & $\mathrm{~N}$ & (c) \\
\hline $\mathrm{J} 0751+2919$ & 13.01 .99 & ST & $\mathrm{R}$ & 8.32 & 56 & 0.362 & 0.3 & 0.5 & 134.70 & 0.93 & $\mathrm{~N}$ & (c) \\
\hline $\mathrm{J} 0751+2919$ & 24.11 .99 & ST & $\mathrm{R}$ & 5.39 & 28 & 0.702 & 0.3 & 0.3 & 42.90 & 0.62 & $\mathrm{~N}$ & (c) \\
\hline $\mathrm{J} 0751+2919$ & 09.12 .99 & ST & $\mathrm{R}$ & 6.21 & 31 & 0.710 & 0.2 & 0.5 & 144.38 & 2.13 & PV & (c) \\
\hline $\mathrm{J} 0751+2919$ & 01.12 .00 & ST & $\mathrm{R}$ & 5.95 & 32 & 0.372 & 0.3 & 0.4 & 63.30 & 0.78 & $\mathrm{~N}$ & (c) \\
\hline $\mathrm{J} 0751+2919$ & 25.12 .01 & ST & $\mathrm{R}$ & 5.44 & 30 & 0.372 & 0.4 & 0.4 & 36.78 & 0.54 & $\mathrm{~N}$ & (c) \\
\hline $\mathrm{J} 0751+2919$ & 17.12.04 & $\mathrm{HCT}$ & $\mathrm{V}$ & 3.69 & 15 & 0.318 & 0.1 & 0.2 & 24.61 & 0.74 & $\mathrm{~N}$ & (b) \\
\hline $\mathrm{J} 0751+2919$ & 17.12 .04 & ST & $\mathrm{R}$ & 7.02 & 34 & 0.238 & 0.1 & 0.3 & 130.66 & 1.56 & $\mathrm{~N}$ & (b) \\
\hline $\mathrm{J} 0751+2919$ & 12.01 .05 & ST & $\mathrm{R}$ & 7.15 & 16 & 0.129 & 0.1 & 0.2 & 22.10 & 0.61 & $\mathrm{~N}$ & (b) \\
\hline $\mathrm{J} 0751+2919$ & 07.03.06 & HCT & $\mathrm{R}$ & 8.06 & 29 & 0.046 & 0.1 & 0.2 & 55.95 & 0.84 & $\mathrm{~N}$ & (b) \\
\hline J0751+2919 & 07.03 .06 & ST & $\mathrm{R}$ & 8.33 & 46 & 0.079 & 0.1 & 0.2 & 141.20 & 1.32 & $\mathrm{~N}$ & (b) \\
\hline $\mathrm{J} 0827+0942$ & 27.12.98 & ST & $\mathrm{R}$ & 8.15 & 60 & 0.415 & 0.3 & 0.4 & 119.04 & 0.88 & $\mathrm{~N}$ & (a) \\
\hline J0827+0942 & 13.01 .05 & HCT & V & 6.47 & 16 & 0.061 & 0.1 & 0.2 & 24.02 & 0.67 & $\mathrm{~N}$ & (b) \\
\hline J0827+0942 & 13.01 .05 & ST & $\mathrm{R}$ & 6.94 & 17 & 0.000 & 0.1 & 0.2 & 44.74 & 1.18 & $\mathrm{~N}$ & (b) \\
\hline $\mathrm{J} 0835+2506$ & 25.12 .98 & ST & $\mathrm{R}$ & 4.68 & 26 & 0.911 & 0.4 & 0.6 & 67.49 & 1.13 & $\mathrm{~N}$ & (a) \\
\hline $\mathrm{J} 0835+2506$ & 14.01 .99 & ST & $\mathrm{R}$ & 8.91 & 78 & 0.206 & 0.4 & 0.6 & 169.41 & 0.92 & $\mathrm{~N}$ & (a) \\
\hline $\mathrm{J} 0835+2506$ & 10.12 .99 & ST & $\mathrm{R}$ & 6.72 & 33 & 0.714 & 0.4 & 0.6 & 59.65 & 0.75 & $\mathrm{~N}$ & (a) \\
\hline J0853+4349 & 17.02 .99 & ST & $\mathrm{R}$ & 7.70 & 39 & 0.234 & 0.4 & 0.7 & 91.50 & 0.99 & $\mathrm{~N}$ & (a) \\
\hline $\mathrm{J} 0935+4331$ & 20.02 .99 & ST & $\mathrm{R}$ & 4.47 & 26 & 0.883 & 0.2 & 0.3 & 106.91 & 1.69 & $\mathrm{~N}$ & (a) \\
\hline J0938+4128 & 27.03.99 & ST & $\mathrm{R}$ & 2.73 & 17 & 0.000 & 0.5 & 0.6 & 34.40 & 0.73 & $\mathrm{~N}$ & (a) \\
\hline J0948+4335 & 15.01 .99 & ST & $\mathrm{R}$ & 7.97 & 44 & 0.209 & 0.3 & 0.5 & 79.10 & 0.80 & $\mathrm{~N}$ & (c) \\
\hline $\mathrm{J} 0948+4335$ & 26.02 .00 & ST & $\mathrm{R}$ & 7.97 & 39 & 0.490 & 0.4 & 0.6 & 82.44 & 0.91 & $\mathrm{~N}$ & (c) \\
\hline $\mathrm{J} 0948+4335$ & 23.01 .01 & ST & $\mathrm{R}$ & 6.73 & 25 & 0.505 & 0.3 & 0.6 & 77.02 & 1.20 & $\mathrm{~N}$ & (c) \\
\hline $\mathrm{J} 1019+2744$ & 14.03 .99 & ST & $\mathrm{R}$ & 7.32 & 43 & 0.304 & 0.5 & 0.7 & 92.57 & 0.86 & $\mathrm{~N}$ & (c) \\
\hline $\mathrm{J} 1019+2744$ & 14.01 .00 & ST & $\mathrm{R}$ & 7.08 & 34 & 0.441 & 0.2 & 0.2 & 42.28 & 0.52 & $\mathrm{~N}$ & (c) \\
\hline $\mathrm{J} 1019+2744$ & 27.02 .00 & ST & $\mathrm{R}$ & 8.81 & 37 & 0.442 & 0.2 & 0.3 & 63.77 & 0.61 & $\mathrm{~N}$ & (c) \\
\hline $\mathrm{J} 1032+3240$ & 13.03.99 & VBT & $\mathrm{V}$ & 8.40 & 45 & 0.503 & 0.5 & 0.8 & 158.00 & 1.16 & $\mathrm{~N}$ & (c) \\
\hline $\mathrm{J} 1032+3240$ & 02.03 .00 & ST & $\mathrm{R}$ & 4.95 & 19 & 0.887 & 0.2 & 0.4 & 64.64 & 1.45 & $\mathrm{~N}$ & (c) \\
\hline $\mathrm{J} 1032+3240$ & 05.04 .00 & ST & $\mathrm{R}$ & 6.17 & 24 & 0.136 & 0.1 & 0.3 & 108.19 & 1.85 & PV & (c) \\
\hline $\mathrm{J} 1032+3240$ & 23.03 .01 & ST & $\mathrm{R}$ & 6.84 & 25 & 0.303 & 0.5 & 0.6 & 51.32 & 0.83 & $\mathrm{~N}$ & (c) \\
\hline $\mathrm{J} 1032+3240$ & 06.03 .02 & ST & $\mathrm{R}$ & 8.53 & 34 & 0.134 & 0.2 & 0.3 & 185.91 & 1.28 & $\mathrm{~N}$ & (c) \\
\hline $\mathrm{J} 1032+3240$ & 08.03 .02 & ST & $\mathrm{R}$ & 8.31 & 24 & 0.127 & 0.2 & 0.3 & 75.22 & 1.17 & $\mathrm{~N}$ & (c) \\
\hline $\mathrm{J} 1104+3141$ & 12.03 .99 & ST & $\mathrm{R}$ & 8.80 & 43 & 0.551 & 0.6 & 0.7 & 51.55 & 0.48 & $\mathrm{~N}$ & (c) \\
\hline $\mathrm{J} 1104+3141$ & 14.04 .00 & ST & $\mathrm{R}$ & 5.61 & 22 & 0.035 & 0.3 & 0.5 & 62.25 & 1.01 & $\mathrm{~N}$ & (c) \\
\hline $\mathrm{J} 1104+3141$ & 21.04 .01 & ST & $\mathrm{R}$ & 6.40 & 27 & 0.032 & 0.5 & 0.5 & 28.59 & 0.41 & $\mathrm{~N}$ & (c) \\
\hline $\mathrm{J} 1104+3141$ & 22.04 .01 & ST & $\mathrm{R}$ & 5.58 & 24 & 0.037 & 0.5 & 0.5 & 27.08 & 0.43 & $\mathrm{~N}$ & (c) \\
\hline $\mathrm{J} 1119+2119$ & 14.04 .05 & ST & $\mathrm{R}$ & 5.02 & 30 & 0.065 & 0.1 & 0.2 & 48.37 & 0.70 & $\mathrm{~N}$ & (b) \\
\hline $\mathrm{J} 1119+2119$ & 30.03 .06 & ST & $\mathrm{R}$ & 6.17 & 41 & 0.072 & 0.1 & 0.3 & 149.11 & 1.57 & $\mathrm{~N}$ & (b) \\
\hline $\mathrm{J} 1119+2119$ & 31.03 .06 & ST & $\mathrm{R}$ & 4.25 & 26 & 0.070 & 0.1 & 0.2 & 49.47 & 0.83 & $\mathrm{~N}$ & (b) \\
\hline $\mathrm{J} 1246+0224$ & 13.04 .05 & ST & $\mathrm{R}$ & 5.51 & 10 & 0.046 & 0.1 & 0.3 & 48.90 & 2.01 & $\mathrm{~N}$ & (b) \\
\hline
\end{tabular}


Table 1 (cont'd)

\begin{tabular}{|c|c|c|c|c|c|c|c|c|c|c|c|c|}
\hline $\begin{array}{l}\text { AGN } \\
\text { name } \\
(1)\end{array}$ & $\begin{array}{l}\text { Obs. date } \\
\text { dd.mm.yy } \\
\text { (2) }\end{array}$ & $\begin{array}{l}\text { Tel. }{ }^{\text {II }} \\
\text { used } \\
\text { (3) }\end{array}$ & $\begin{array}{c}\text { Filter. } \\
\text { used } \\
\text { (4) }\end{array}$ & $\begin{array}{l}\text { Dur. } \\
(\mathrm{hr}) \\
(5)\end{array}$ & $\begin{array}{l}N_{p} \\
\text { (6) }\end{array}$ & $\begin{array}{c}\Delta m_{s} \\
(\mathrm{mag}) \\
(7)\end{array}$ & $\begin{array}{c}\sigma \\
\left(10^{-2} \mathrm{mag}\right) \\
(8)\end{array}$ & $\begin{array}{c}\text { std dev. } \\
\left(10^{-2} \mathrm{mag}\right) \\
(9)\end{array}$ & $\begin{array}{l}\chi_{s}^{2} \\
(10)\end{array}$ & $\begin{array}{l}F_{S} \\
(11)\end{array}$ & $\begin{array}{l}\text { Status }{ }^{\dagger} \\
\text { (12) }\end{array}$ & $\begin{array}{r}\operatorname{Ref}^{f} \\
\text { (13) }\end{array}$ \\
\hline $\mathrm{J} 1255+0144$ & 22.03.99 & ST & $\mathrm{R}$ & 7.46 & 43 & 0.483 & 0.4 & 0.5 & 64.91 & 0.59 & $\mathrm{~N}$ & (c) \\
\hline $\mathrm{J} 1255+0144$ & 09.03.00 & ST & $\mathrm{R}$ & 6.14 & 29 & 0.144 & 0.1 & 0.2 & 80.28 & 1.05 & $\mathrm{~N}$ & (c) \\
\hline $\mathrm{J} 1255+0144$ & 03.04 .00 & ST & $\mathrm{R}$ & 4.32 & 21 & 0.154 & 0.1 & 0.4 & 109.28 & 2.53 & $\mathrm{~V}$ & (c) \\
\hline $\mathrm{J} 1255+0144$ & 26.04 .01 & ST & $\mathrm{R}$ & 4.60 & 20 & 0.107 & 0.2 & 0.5 & 136.56 & 1.88 & $\mathrm{~N}$ & (c) \\
\hline $\mathrm{J} 1255+0144$ & 18.03 .02 & ST & $\mathrm{R}$ & 7.88 & 25 & 0.130 & 0.4 & 0.3 & 73.50 & 0.36 & $\mathrm{~N}$ & (c) \\
\hline $\mathrm{J} 1424+4214$ & 03.04.99 & ST & $\mathrm{R}$ & 7.22 & 41 & 0.056 & 0.3 & 0.6 & 158.64 & 1.48 & $\mathrm{~N}$ & (a) \\
\hline $\mathrm{J} 1424+4214$ & 07.03 .00 & ST & $\mathrm{R}$ & 3.88 & 15 & 0.380 & 0.2 & 0.3 & 55.01 & 1.34 & $\mathrm{~N}$ & (a) \\
\hline $\mathrm{J} 1424+4214$ & 08.03 .00 & GSO & V & 3.05 & 30 & 0.385 & 0.6 & 0.8 & 54.71 & 0.76 & $\mathrm{~N}$ & (a) \\
\hline $\mathrm{J} 1524+0958$ & 11.04 .99 & ST & $\mathrm{R}$ & 6.55 & 38 & 0.491 & 0.2 & 0.3 & 78.81 & 0.96 & $\mathrm{~N}$ & (a) \\
\hline $\mathrm{J} 1528+2825$ & 10.05 .05 & ST & $\mathrm{R}$ & 7.75 & 16 & 0.065 & 0.2 & 0.2 & 27.00 & 0.33 & $\mathrm{~N}$ & (b) \\
\hline $\mathrm{J} 1631+2953$ & 15.06 .04 & HCT & V & 6.21 & 28 & 1.110 & 0.2 & 0.4 & 64.31 & 1.00 & $\mathrm{~N}$ & (b) \\
\hline $\mathrm{J} 1631+2953$ & 11.05 .05 & ST & $\mathrm{R}$ & 6.92 & 29 & 0.006 & 0.3 & 0.4 & 53.36 & 0.62 & $\mathrm{~N}$ & (b) \\
\hline $\mathrm{J} 1631+2953$ & 01.06 .05 & ST & $\mathrm{R}$ & 7.36 & 15 & 1.369 & 0.2 & 0.4 & 30.35 & 0.93 & $\mathrm{~N}$ & (b) \\
\hline $\mathrm{J} 1632+3737$ & 12.05 .05 & ST & $\mathrm{R}$ & 6.60 & 29 & 0.289 & 0.2 & 0.2 & 53.95 & 0.72 & $\mathrm{~N}$ & (b) \\
\hline $\mathrm{J} 1751+5045$ & 03.06.98 & ST & $\mathrm{R}$ & 4.72 & 46 & 0.373 & 0.2 & 0.3 & 109.29 & 1.00 & $\mathrm{~N}$ & (a) \\
\hline $\mathrm{J} 1751+5045$ & 06.06 .98 & ST & $\mathrm{R}$ & 1.65 & 17 & 0.384 & 0.3 & 0.4 & 32.15 & 0.93 & $\mathrm{~N}$ & (a) \\
\hline $\mathrm{J} 1751+5045$ & 08.06 .98 & ST & $\mathrm{R}$ & 6.15 & 36 & 0.021 & 0.2 & 0.3 & 157.64 & 1.78 & PV & (a) \\
\hline \multicolumn{13}{|c|}{ Radio intermediate quasars (RIQs)[10 sources; 31 DLCs] } \\
\hline $\mathrm{J} 0005+1609$ & 03.11 .00 & ST & $\mathrm{R}$ & 6.55 & 30 & 0.302 & 0.3 & 0.3 & 44.85 & 0.61 & $\mathrm{~N}$ & (a) \\
\hline $\mathrm{J} 0005+1609$ & 05.11 .00 & ST & $\mathrm{R}$ & 7.74 & 39 & 0.028 & 0.4 & 0.3 & 28.94 & 0.30 & $\mathrm{~N}$ & (a) \\
\hline $\mathrm{J} 0748+2200$ & 19.01.07 & ST & $\mathrm{R}$ & 5.20 & 19 & 0.030 & 0.3 & 0.3 & 28.12 & 0.62 & $\mathrm{~N}$ & (d) \\
\hline $\mathrm{J} 0748+2200$ & 23.01.07 & ST & $\mathrm{R}$ & 7.21 & 25 & 0.149 & 0.3 & 0.4 & 38.97 & 0.64 & $\mathrm{~N}$ & (d) \\
\hline $\mathrm{J} 0748+2200$ & 19.02.07 & ST & $\mathrm{R}$ & 6.42 & 24 & 0.614 & 0.3 & 0.4 & 77.17 & 1.24 & $\mathrm{~N}$ & (d) \\
\hline $\mathrm{J} 0748+2200$ & 29.01.08 & IGO & $\mathrm{R}$ & 5.41 & 19 & 0.627 & 0.1 & 0.1 & 17.96 & 0.42 & $\mathrm{~N}$ & (d) \\
\hline $\mathrm{J} 0748+2200$ & 30.01 .08 & IGO & $\mathrm{R}$ & 6.03 & 20 & 0.805 & 0.1 & 0.2 & 33.25 & 0.67 & $\mathrm{~N}$ & (d) \\
\hline $\mathrm{J} 0832+3707$ & 23.01.07 & HCT & $\mathrm{R}$ & 4.91 & 29 & 0.265 & 0.2 & 0.2 & 60.16 & 0.88 & $\mathrm{~N}$ & (d) \\
\hline $\mathrm{J} 0832+3707$ & 21.02 .07 & ST & $\mathrm{R}$ & 4.70 & 21 & 0.193 & 0.1 & 0.2 & 43.88 & 0.92 & $\mathrm{~N}$ & (d) \\
\hline $\mathrm{J} 0832+3707$ & 10.03.07 & IGO & $\mathrm{R}$ & 5.04 & 10 & 0.203 & 0.2 & 0.2 & 11.06 & 0.59 & $\mathrm{~N}$ & (d) \\
\hline J0832+3707 & 11.03 .07 & IGO & $\mathrm{R}$ & 5.09 & 10 & 0.204 & 0.2 & 0.3 & 23.95 & 1.16 & $\mathrm{~N}$ & (d) \\
\hline $\mathrm{J} 0836+4426$ & 22.01 .07 & ST & $\mathrm{R}$ & 5.61 & 24 & 1.288 & 0.2 & 0.2 & 19.63 & 0.35 & $\mathrm{~N}$ & (d) \\
\hline $\mathrm{J} 0836+4426$ & 10.02 .07 & IGO & $\mathrm{R}$ & 5.58 & 15 & 0.815 & 0.2 & 0.3 & 36.26 & 1.00 & $\mathrm{~N}$ & (d) \\
\hline $\mathrm{J} 0836+4426$ & 09.03.07 & IGO & $\mathrm{R}$ & 5.16 & 16 & 0.864 & 0.2 & 0.3 & 39.16 & 1.49 & $\mathrm{~N}$ & (d) \\
\hline J0907+5515 & 04.02.08 & IGO & $\mathrm{R}$ & 8.99 & 24 & 0.247 & 0.2 & 0.3 & 47.80 & 0.75 & $\mathrm{~N}$ & (d) \\
\hline J0907+5515 & 05.02 .08 & IGO & $\mathrm{R}$ & 7.48 & 13 & 0.365 & 0.1 & 0.3 & 40.08 & 1.33 & $\mathrm{~N}$ & (d) \\
\hline $\mathrm{J} 1259+3423$ & 19.04.07 & ST & $\mathrm{R}$ & 5.40 & 21 & 0.673 & 0.2 & 0.4 & 95.09 & 1.63 & $\mathrm{~N}$ & (d) \\
\hline $\mathrm{J} 1259+3423$ & 20.04.07 & ST & $\mathrm{R}$ & 6.40 & 27 & 0.673 & 0.2 & 0.3 & 66.00 & 0.80 & $\mathrm{~N}$ & (d) \\
\hline $\mathrm{J} 1259+3423$ & 24.04 .07 & ST & $\mathrm{R}$ & 5.30 & 22 & 0.688 & 0.2 & 0.3 & 41.81 & 0.79 & $\mathrm{~N}$ & (d) \\
\hline $\mathrm{J} 1312+3515$ & 25.03.99 & ST & $\mathrm{R}$ & 6.67 & 39 & 0.097 & 0.2 & 0.5 & 398.57 & 2.79 & $\mathrm{~V}$ & (e) \\
\hline $\mathrm{J} 1312+3515$ & 01.04 .01 & ST & $\mathrm{R}$ & 4.87 & 32 & 0.443 & 0.2 & 0.4 & 149.98 & 2.52 & V & (e) \\
\hline $\mathrm{J} 1312+3515$ & 02.04 .01 & ST & $\mathrm{R}$ & 5.19 & 41 & 0.696 & 0.3 & 0.4 & 86.44 & 0.81 & $\mathrm{~N}$ & (e) \\
\hline $\mathrm{J} 1336+1725$ & 11.04 .05 & ST & $\mathrm{R}$ & 7.93 & 29 & 0.305 & 0.1 & 0.2 & 53.60 & 0.80 & $\mathrm{~N}$ & (d) \\
\hline $\mathrm{J} 1336+1725$ & 08.05 .05 & ST & $\mathrm{R}$ & 4.47 & 17 & 0.739 & 0.2 & 0.3 & 60.18 & 1.53 & $\mathrm{~N}$ & (d) \\
\hline $\mathrm{J} 1336+1725$ & 13.04 .08 & ST & $\mathrm{R}$ & 8.06 & 20 & 0.731 & 0.2 & 0.3 & 56.65 & 1.33 & $\mathrm{~N}$ & (d) \\
\hline $\mathrm{J} 1539+4735$ & 27.05 .09 & ST & $\mathrm{R}$ & 6.26 & 30 & 0.776 & 0.3 & 0.4 & 52.69 & 0.69 & $\mathrm{~N}$ & (d) \\
\hline $\mathrm{J} 1539+4735$ & 02.06 .09 & ST & $\mathrm{R}$ & 7.03 & 30 & 0.779 & 0.4 & 0.5 & 56.11 & 0.68 & $\mathrm{~N}$ & (d) \\
\hline $\mathrm{J} 1539+4735$ & 14.06 .09 & ST & $\mathrm{R}$ & 5.30 & 24 & 0.776 & 0.4 & 0.5 & 36.33 & 0.54 & $\mathrm{~N}$ & (d) \\
\hline $\mathrm{J} 1719+4804$ & 29.04.06 & ST & $\mathrm{R}$ & 4.88 & 25 & 0.131 & 0.1 & 0.2 & 54.32 & 0.95 & $\mathrm{~N}$ & (d) \\
\hline $\mathrm{J} 1719+4804$ & 30.04 .06 & ST & $\mathrm{R}$ & 5.64 & 22 & 0.195 & 0.1 & 0.2 & 61.02 & 1.22 & $\mathrm{~N}$ & (d) \\
\hline $\mathrm{J} 1719+4804$ & 30.05 .06 & ST & $\mathrm{R}$ & 6.06 & 26 & 0.031 & 0.2 & 0.3 & 62.64 & 0.85 & $\mathrm{~N}$ & (d) \\
\hline
\end{tabular}


Table 1 (cont'd)

\begin{tabular}{|c|c|c|c|c|c|c|c|c|c|c|c|c|}
\hline $\begin{array}{c}\text { AGN } \\
\text { name } \\
(1)\end{array}$ & $\begin{array}{l}\text { Obs. date } \\
\text { dd.mm.yy } \\
\text { (2) }\end{array}$ & $\begin{array}{l}\text { Tel. }^{\mathbb{T}} \\
\text { used } \\
\text { (3) }\end{array}$ & $\begin{array}{c}\text { Filter. } \\
\text { used } \\
\text { (4) }\end{array}$ & $\begin{array}{c}\text { Dur. } \\
\text { (hr) } \\
(5)\end{array}$ & $\begin{array}{l}N_{p} \\
\text { (6) }\end{array}$ & $\begin{array}{c}\Delta m_{s} \\
(\mathrm{mag}) \\
(7)\end{array}$ & $\begin{array}{c}\sigma \\
\left(10^{-2} \mathrm{mag}\right) \\
(8)\end{array}$ & $\begin{array}{c}\text { std dev. } \\
\left(10^{-2} \mathrm{mag}\right) \\
(9)\end{array}$ & $\begin{array}{l}\chi_{s}^{2} \\
(10)\end{array}$ & $\begin{array}{l}F_{s} \\
(11)\end{array}$ & $\begin{array}{c}\text { Status }^{\dagger} \\
\text { (12) }\end{array}$ & $\begin{array}{r}\operatorname{Ref}^{f} \\
\text { (13) }\end{array}$ \\
\hline $\mathrm{J} 0015+3052$ & 18.01 .01 & ST & $\mathrm{R}$ & 3.78 & 18 & 0.241 & 0.5 & 0.5 & 21.29 & 0.40 & $\mathrm{~N}$ & (c) \\
\hline $\mathrm{J} 0015+3052$ & 20.01 .01 & ST & $\mathrm{R}$ & 2.70 & 12 & 0.457 & 0.6 & 0.3 & 4.66 & 0.16 & $\mathrm{~N}$ & (c) \\
\hline J0015+3052 & 24.01 .01 & ST & $\mathrm{R}$ & 2.87 & 14 & 0.242 & 0.6 & 0.5 & 9.82 & 0.25 & $\mathrm{~N}$ & (c) \\
\hline J0015+3052 & 14.10 .01 & ST & $\mathrm{R}$ & 6.78 & 26 & 0.235 & 0.6 & 0.7 & 37.85 & 0.51 & $\mathrm{~N}$ & (c) \\
\hline $\mathrm{J} 0015+3052$ & 21.10 .01 & ST & $\mathrm{R}$ & 6.25 & 24 & 0.703 & 0.5 & 0.5 & 17.98 & 0.36 & $\mathrm{~N}$ & (c) \\
\hline $\mathrm{J} 0028+3103$ & 13.10 .98 & ST & $\mathrm{R}$ & 3.60 & 28 & 0.241 & 0.1 & 0.2 & 57.87 & 0.90 & $\mathrm{~N}$ & (a) \\
\hline $\mathrm{J} 0028+3103$ & 01.11 .98 & ST & $\mathrm{R}$ & 3.35 & 26 & 0.260 & 0.2 & 0.3 & 76.98 & 1.14 & $\mathrm{~N}$ & (a) \\
\hline J0137+3309 & 07.11 .01 & ST & $\mathrm{R}$ & 6.54 & 36 & 0.089 & 0.6 & 0.5 & 88.24 & 0.28 & $\mathrm{~N}$ & (c) \\
\hline J0137+3309 & 08.11 .01 & ST & $\mathrm{R}$ & 6.66 & 32 & 0.132 & 0.3 & 0.4 & 58.61 & 0.70 & $\mathrm{~N}$ & (c) \\
\hline $\mathrm{J} 0137+3309$ & 13.11 .01 & ST & $\mathrm{R}$ & 8.63 & 46 & 0.213 & 0.3 & 0.4 & 119.10 & 1.07 & $\mathrm{~N}$ & (c) \\
\hline $\mathrm{J} 0352-0711$ & 14.11 .01 & ST & $\mathrm{R}$ & 6.56 & 31 & 0.617 & 0.2 & 0.3 & 70.99 & 0.80 & $\mathrm{~N}$ & (c) \\
\hline J0352-0711 & 15.11 .01 & ST & $\mathrm{R}$ & 5.54 & 26 & 0.630 & 0.2 & 0.3 & 39.30 & 0.66 & $\mathrm{~N}$ & (c) \\
\hline J0352-0711 & 18.11 .01 & ST & $\mathrm{R}$ & 5.70 & 25 & 0.628 & 0.2 & 0.4 & 106.55 & 1.42 & $\mathrm{~N}$ & (c) \\
\hline $\mathrm{J} 0713+3656$ & 20.01 .01 & ST & $\mathrm{R}$ & 6.51 & 29 & 0.191 & 0.3 & 0.3 & 45.90 & 0.72 & $\mathrm{~N}$ & (c) \\
\hline $\mathrm{J} 0713+3656$ & 21.01 .01 & ST & $\mathrm{R}$ & 6.40 & 30 & 0.190 & 0.3 & 0.3 & 42.60 & 0.61 & $\mathrm{~N}$ & (c) \\
\hline $\mathrm{J} 0713+3656$ & 25.01 .01 & ST & $\mathrm{R}$ & 7.08 & 31 & 0.453 & 0.3 & 0.3 & 46.97 & 0.66 & $\mathrm{~N}$ & (c) \\
\hline $\mathrm{J} 0713+3656$ & 20.12 .01 & ST & $\mathrm{R}$ & 8.07 & 52 & 0.202 & 0.3 & 0.6 & 190.47 & 1.56 & $\mathrm{~N}$ & (c) \\
\hline $\mathrm{J} 0713+3656$ & 21.12 .01 & ST & $\mathrm{R}$ & 7.49 & 48 & 0.449 & 0.2 & 0.4 & 142.06 & 1.20 & $\mathrm{~N}$ & (c) \\
\hline $\mathrm{J} 1007+1248$ & 16.02 .99 & ST & $\mathrm{R}$ & 6.51 & 36 & 1.000 & 0.1 & 0.3 & 213.36 & 2.42 & V & (c) \\
\hline $\mathrm{J} 1007+1248$ & 27.02.99 & ST & $\mathrm{R}$ & 4.27 & 30 & 0.996 & 0.4 & 0.4 & 39.70 & 0.51 & $\mathrm{~N}$ & (c) \\
\hline $\mathrm{J} 1007+1248$ & 29.03 .00 & ST & $\mathrm{R}$ & 3.81 & 21 & 1.012 & 0.1 & 0.2 & 58.34 & 1.23 & $\mathrm{~N}$ & (c) \\
\hline $\mathrm{J} 1007+1248$ & 30.03 .00 & ST & $\mathrm{R}$ & 4.64 & 26 & 1.007 & 0.2 & 0.3 & 71.58 & 0.83 & $\mathrm{~N}$ & (c) \\
\hline $\mathrm{J} 1007+1248$ & 18.02 .01 & ST & $\mathrm{R}$ & 5.54 & 42 & 1.015 & 0.2 & 0.4 & 112.96 & 1.16 & $\mathrm{~N}$ & (c) \\
\hline $\mathrm{J} 1007+1248$ & 24.03 .01 & ST & $\mathrm{R}$ & 6.38 & 50 & 1.011 & 0.2 & 0.4 & 297.51 & 1.91 & PV & (c) \\
\hline J1106-0052 & 17.03.99 & ST & $\mathrm{R}$ & 3.81 & 23 & 0.347 & 0.3 & 0.5 & 65.59 & 1.23 & $\mathrm{~N}$ & (c) \\
\hline J1106-0052 & 18.03 .99 & ST & $\mathrm{R}$ & 7.51 & 42 & 0.348 & 0.3 & 0.5 & 107.03 & 0.99 & $\mathrm{~N}$ & (c) \\
\hline J1106-0052 & 16.04 .00 & ST & $\mathrm{R}$ & 3.85 & 15 & 0.348 & 0.3 & 0.4 & 36.16 & 0.78 & $\mathrm{~N}$ & (c) \\
\hline $\mathrm{J} 1106-0052$ & 25.03 .01 & ST & $\mathrm{R}$ & 7.18 & 28 & 0.343 & 0.3 & 0.4 & 49.79 & 0.70 & $\mathrm{~N}$ & (c) \\
\hline J1106-0052 & 14.04 .01 & ST & $\mathrm{R}$ & 4.55 & 19 & 0.346 & 0.3 & 0.5 & 86.90 & 1.50 & $\mathrm{~N}$ & (c) \\
\hline J1106-0052 & 22.03 .02 & ST & $\mathrm{R}$ & 6.13 & 18 & 0.342 & 0.2 & 0.3 & 32.21 & 0.78 & $\mathrm{~N}$ & (c) \\
\hline $\mathrm{J} 1633+3924$ & 04.06 .99 & ST & $\mathrm{R}$ & 5.71 & 30 & 0.293 & 0.6 & 0.6 & 28.75 & 0.45 & $\mathrm{~N}$ & (a) \\
\hline $\mathrm{J} 1633+3924$ & 30.05 .00 & ST & $\mathrm{R}$ & 3.54 & 14 & 0.542 & 0.5 & 0.6 & 15.95 & 0.52 & $\mathrm{~N}$ & (a) \\
\hline J2351-0109 & 13.10 .01 & ST & $\mathrm{R}$ & 7.56 & 41 & 0.163 & 0.2 & 0.4 & 213.75 & 1.43 & $\mathrm{~N}$ & (c) \\
\hline J2351-0109 & 17.10 .01 & ST & $\mathrm{R}$ & 7.80 & 43 & 0.032 & 0.2 & 0.3 & 153.36 & 1.17 & $\mathrm{~N}$ & (c) \\
\hline J2351-0109 & 18.10 .01 & ST & $\mathrm{R}$ & 8.40 & 46 & 0.032 & 0.2 & 0.2 & 96.62 & 0.72 & $\mathrm{~N}$ & (c) \\
\hline \multicolumn{13}{|c|}{ Low optical polarization core dominated quasars (LPCDQs)[12 sources; 43 DLCs] } \\
\hline $\mathrm{J} 0005+0524$ & 23.10 .06 & ST & $\mathrm{R}$ & 7.05 & 16 & 0.132 & 0.3 & 0.2 & 11.64 & 0.31 & $\mathrm{~N}$ & (f) \\
\hline J0005+0524 & 18.11 .06 & ST & $\mathrm{R}$ & 4.69 & 11 & 0.394 & 0.2 & 0.1 & 6.30 & 0.24 & $\mathrm{~N}$ & (f) \\
\hline $\mathrm{J} 0005+0524$ & 14.09 .07 & ST & $\mathrm{R}$ & 5.31 & 12 & 0.370 & 0.2 & 0.4 & 30.33 & 1.14 & $\mathrm{~N}$ & (f) \\
\hline $\mathrm{J} 0005+0524$ & 16.09 .07 & ST & $\mathrm{R}$ & 6.11 & 13 & 0.240 & 0.2 & 0.4 & 81.99 & 2.15 & $\mathrm{~N}$ & (f) \\
\hline J0235-0402 & 21.10 .04 & ST & $\mathrm{R}$ & 7.25 & 15 & 0.127 & 0.1 & 0.2 & 43.88 & 1.15 & $\mathrm{~N}$ & (f) \\
\hline J0235-0402 & 22.10 .04 & ST & $\mathrm{R}$ & 7.87 & 17 & 0.244 & 0.2 & 0.2 & 43.75 & 0.82 & $\mathrm{~N}$ & (f) \\
\hline J0235-0402 & 04.11 .04 & ST & $\mathrm{R}$ & 6.19 & 25 & 0.249 & 0.2 & 0.2 & 36.34 & 0.51 & $\mathrm{~N}$ & (f) \\
\hline J0235-0402 & 05.11 .04 & ST & $\mathrm{R}$ & 7.27 & 29 & 0.122 & 0.1 & 0.2 & 68.37 & 1.01 & $\mathrm{~N}$ & (f) \\
\hline J0456+0400 & 23.11 .08 & ST & $\mathrm{R}$ & 5.50 & 24 & 0.405 & 0.2 & 0.3 & 43.41 & 0.79 & $\mathrm{~N}$ & (f) \\
\hline $\mathrm{J} 0456+0400$ & 29.11 .08 & ST & $\mathrm{R}$ & 5.51 & 20 & 0.404 & 0.2 & 0.3 & 36.82 & 0.82 & $\mathrm{~N}$ & (f) \\
\hline $\mathrm{J} 0456+0400$ & 03.12 .08 & ST & $\mathrm{R}$ & 5.38 & 22 & 0.529 & 0.3 & 0.3 & 28.65 & 0.59 & $\mathrm{~N}$ & (f) \\
\hline $\mathrm{J} 0741+3112$ & 20.01 .06 & ST & $\mathrm{R}$ & 7.42 & 31 & 0.614 & 0.2 & 0.3 & 78.51 & 0.94 & $\mathrm{~N}$ & (f) \\
\hline $\mathrm{J} 0741+3112$ & 21.01 .06 & ST & $\mathrm{R}$ & 4.01 & 18 & 0.766 & 0.2 & 0.3 & 26.33 & 0.63 & $\mathrm{~N}$ & (f) \\
\hline $\mathrm{J} 0741+3112$ & 18.12 .06 & ST & $\mathrm{R}$ & 7.24 & 29 & 0.135 & 0.1 & 0.2 & 95.05 & 1.42 & $\mathrm{~N}$ & (f) \\
\hline $\mathrm{J} 0741+3112$ & 22.12 .06 & ST & $\mathrm{R}$ & 7.72 & 32 & 0.140 & 0.1 & 0.2 & 58.35 & 0.79 & $\mathrm{~N}$ & (f) \\
\hline J0842+1835 & 04.02 .06 & ST & $\mathrm{R}$ & 7.64 & 28 & 0.274 & 0.1 & 0.2 & 59.41 & 0.92 & $\mathrm{~N}$ & (f) \\
\hline $\mathrm{J} 0842+1835$ & 16.12 .06 & ST & $\mathrm{R}$ & 5.96 & 14 & 0.277 & 0.1 & 0.4 & 83.30 & 2.57 & $\mathrm{~N}$ & (f) \\
\hline J0842+1835 & 21.12 .06 & ST & $\mathrm{R}$ & 6.94 & 30 & 0.279 & 0.1 & 0.2 & 92.31 & 1.23 & $\mathrm{~N}$ & (f) \\
\hline
\end{tabular}


Table 1 (cont'd)

\begin{tabular}{|c|c|c|c|c|c|c|c|c|c|c|c|c|}
\hline $\begin{array}{c}\text { AGN } \\
\text { name } \\
\text { (1) }\end{array}$ & $\begin{array}{l}\text { Obs. date } \\
\text { dd.mm.yy } \\
\text { (2) }\end{array}$ & $\begin{array}{c}\text { Tel. II } \\
\text { used } \\
\text { (3) }\end{array}$ & $\begin{array}{c}\text { Filter. } \\
\text { used } \\
\text { (4) }\end{array}$ & $\begin{array}{l}\text { Dur. } \\
\text { (hr) } \\
(5)\end{array}$ & $\begin{array}{l}N_{p} \\
\text { (6) }\end{array}$ & $\begin{array}{c}\Delta m_{s} \\
(\mathrm{mag}) \\
(7)\end{array}$ & $\begin{array}{c}\sigma \\
\left(10^{-2} \mathrm{mag}\right) \\
(8)\end{array}$ & $\begin{array}{c}\text { std dev. } \\
\left(10^{-2} \mathrm{mag}\right) \\
(9)\end{array}$ & $\begin{array}{l}\chi_{s}^{2} \\
(10)\end{array}$ & $\begin{array}{l}F_{s} \\
(11)\end{array}$ & $\begin{array}{c}\text { Status }^{\dagger} \\
(12)\end{array}$ & $\begin{array}{r}\operatorname{Ref}^{f} \\
\text { (13) }\end{array}$ \\
\hline $\mathrm{J} 0958+3224$ & 19.02 .99 & ST & $\mathrm{R}$ & 6.50 & 36 & 1.729 & 0.4 & 0.4 & 35.19 & 0.39 & $\mathrm{~N}$ & (e) \\
\hline J0958+3224 & 03.03.00 & ST & $\mathrm{R}$ & 6.29 & 37 & 1.311 & 0.3 & 0.4 & 90.04 & 0.82 & $\mathrm{~N}$ & (e) \\
\hline $\mathrm{J} 0958+3224$ & 05.03 .00 & ST & $\mathrm{R}$ & 6.90 & 34 & 0.430 & 0.1 & 0.3 & 115.79 & 1.48 & $\mathrm{~N}$ & (e) \\
\hline $\mathrm{J} 1131+3114$ & 18.01 .01 & ST & $\mathrm{R}$ & 5.73 & 31 & 0.230 & 0.3 & 0.4 & 59.11 & 0.83 & $\mathrm{~N}$ & (e) \\
\hline $\mathrm{J} 1131+3114$ & 09.03.02 & ST & $\mathrm{R}$ & 8.22 & 27 & 0.435 & 0.3 & 0.3 & 41.50 & 0.52 & $\mathrm{~N}$ & (e) \\
\hline $\mathrm{J} 1131+3114$ & 10.03 .02 & ST & $\mathrm{R}$ & 8.33 & 28 & 0.200 & 0.2 & 0.3 & 46.60 & 0.66 & $\mathrm{~N}$ & (e) \\
\hline $\mathrm{J} 1228+3128$ & 07.03 .99 & ST & $\mathrm{R}$ & 6.63 & 49 & 1.299 & 0.3 & 0.6 & 165.97 & 1.42 & $\mathrm{~N}$ & (e) \\
\hline $\mathrm{J} 1228+3128$ & 07.04.00 & ST & $\mathrm{R}$ & 7.32 & 26 & 1.320 & 0.2 & 0.6 & 150.61 & $2.35 \mathrm{P}$ & V & (e) \\
\hline $\mathrm{J} 1228+3128$ & 20.04 .01 & ST & $\mathrm{R}$ & 7.43 & 34 & 1.357 & 0.6 & 0.7 & 46.63 & 0.59 & $\mathrm{~N}$ & (e) \\
\hline $\mathrm{J} 1229+0203$ & 07.03.11 & ST & $\mathrm{R}$ & 5.46 & 35 & 0.084 & 0.1 & 0.2 & 61.36 & 0.72 & $\mathrm{~N}$ & (f) \\
\hline $\mathrm{J} 1229+0203$ & 10.03 .11 & ST & $\mathrm{R}$ & 6.72 & 49 & 0.047 & 0.1 & 0.2 & 114.60 & 1.00 & $\mathrm{~N}$ & (f) \\
\hline $\mathrm{J} 1357+1919$ & 27.02 .06 & ST & $\mathrm{R}$ & 5.19 & 12 & 0.004 & 0.1 & 0.3 & 45.60 & 1.74 & $\mathrm{~N}$ & (f) \\
\hline $\mathrm{J} 1357+1919$ & 05.03 .06 & ST & $\mathrm{R}$ & 4.94 & 11 & 0.766 & 0.1 & 0.2 & 25.52 & 1.07 & $\mathrm{~N}$ & (f) \\
\hline $\mathrm{J} 1357+1919$ & 26.03 .06 & ST & $\mathrm{R}$ & 6.98 & 12 & 0.025 & 0.1 & 0.5 & 124.20 & 4.76 & V & (f) \\
\hline J1357+1919 & 28.03 .06 & ST & $\mathrm{R}$ & 5.83 & 21 & 0.026 & 0.2 & 0.4 & 110.35 & $2.26 \mathrm{P}$ & V & (f) \\
\hline J1357+1919 & 29.03 .06 & ST & $\mathrm{R}$ & 6.26 & 23 & 0.030 & 0.2 & 0.3 & 110.04 & 1.66 & $\mathrm{~N}$ & (f) \\
\hline J1357+1919 & 06.04 .06 & ST & $\mathrm{R}$ & 7.40 & 27 & 0.746 & 0.2 & 0.3 & 97.85 & 1.28 & $\mathrm{~N}$ & (f) \\
\hline J1357+1919 & 22.04 .06 & ST & $\mathrm{R}$ & 4.88 & 17 & 0.037 & 0.2 & 0.4 & 44.72 & 1.04 & $\mathrm{~N}$ & (f) \\
\hline J1357+1919 & 23.04 .06 & ST & $\mathrm{R}$ & 6.04 & 19 & 0.060 & 0.3 & 0.6 & 95.00 & 1.88 & $\mathrm{~N}$ & (f) \\
\hline $\mathrm{J} 2203+3145$ & 08.11 .05 & HCT & $\mathrm{R}$ & 5.62 & 18 & 0.478 & 0.2 & 0.3 & 92.02 & 1.38 & $\mathrm{~N}$ & (f) \\
\hline $\mathrm{J} 2203+3145$ & 14.09 .06 & ST & $\mathrm{R}$ & 5.87 & 26 & 0.158 & 0.2 & 0.3 & 78.55 & 1.27 & $\mathrm{~N}$ & (f) \\
\hline $\mathrm{J} 2203+3145$ & 15.09 .07 & ST & $\mathrm{R}$ & 7.74 & 33 & 0.511 & 0.2 & 0.2 & 38.25 & 0.75 & $\mathrm{~N}$ & (f) \\
\hline $\mathrm{J} 2346+0930$ & 20.09 .03 & HCT & $\mathrm{R}$ & 5.82 & 39 & 0.772 & 0.1 & 0.3 & 137.92 & 1.65 & $\mathrm{~N}$ & (f) \\
\hline $\mathrm{J} 2346+0930$ & 20.10 .04 & ST & $\mathrm{R}$ & 5.73 & 11 & 0.128 & 0.1 & 0.3 & 52.59 & 2.21 & $\mathrm{~N}$ & (f) \\
\hline $\mathrm{J} 2346+0930$ & 16.11 .06 & ST & $\mathrm{R}$ & 5.24 & 12 & 0.732 & 0.2 & 0.2 & 18.58 & 0.68 & $\mathrm{~N}$ & (f) \\
\hline \multicolumn{13}{|c|}{ High optical polarization core dominated quasars (HPCDQs)[11 sources; 31 DLCs] } \\
\hline $\mathrm{J} 0238+1637$ & 12.11 .99 & ST & $\mathrm{R}$ & 6.57 & 40 & 1.016 & 0.4 & 0.7 & 95.28 & 1.08 & $\mathrm{~N}$ & (e) \\
\hline J0238+1637 & 14.11 .99 & ST & $\mathrm{R}$ & 6.16 & 34 & 1.020 & 0.2 & 0.4 & 88.31 & 1.13 & $\mathrm{~N}$ & (e) \\
\hline $\mathrm{J} 0238+1637$ & 18.11.03 & HCT & $\mathrm{R}$ & 7.80 & 41 & 0.251 & 0.3 & 0.5 & 129.42 & 1.34 & $\mathrm{~N}$ & (f) \\
\hline J0423-0120 & 19.11.03 & HCT & $\mathrm{R}$ & 6.69 & 38 & 0.402 & 0.2 & 0.3 & 153.68 & 1.41 & $\mathrm{~N}$ & (f) \\
\hline $\mathrm{J} 0423-0120$ & 08.12 .04 & ST & $\mathrm{R}$ & 7.00 & 13 & 0.412 & 0.1 & 0.3 & 38.52 & 1.21 & $\mathrm{~N}$ & (f) \\
\hline J0423-0120 & 25.10 .09 & ST & $\mathrm{R}$ & 4.46 & 21 & 0.128 & 0.3 & 0.6 & 76.55 & 1.48 & $\mathrm{~N}$ & (f) \\
\hline $\mathrm{J} 0739+0137$ & 05.12 .05 & HCT & $\mathrm{R}$ & 5.31 & 10 & 0.461 & 0.1 & 0.2 & 20.17 & 0.94 & $\mathrm{~N}$ & (f) \\
\hline J0739+0137 & 06.12 .05 & HCT & $\mathrm{R}$ & 6.06 & 9 & 0.647 & 0.1 & 0.4 & 80.48 & 4.24 & PV & (f) \\
\hline J0739+0137 & 09.12 .05 & HCT & $\mathrm{R}$ & 5.46 & 14 & 0.186 & 0.1 & 0.3 & 57.77 & 1.87 & $\mathrm{~N}$ & (f) \\
\hline $\mathrm{J} 0849+5108$ & 30.12 .98 & ST & $\mathrm{R}$ & 7.08 & 39 & 0.603 & 0.8 & 1.3 & 116.19 & 1.18 & $\mathrm{~N}$ & (a) \\
\hline $\mathrm{J} 1058+0133$ & 25.03 .07 & ST & $\mathrm{R}$ & 6.87 & 13 & 0.177 & 0.1 & 0.2 & 21.51 & 0.81 & $\mathrm{~N}$ & (f) \\
\hline $\mathrm{J} 1058+0133$ & 16.04 .07 & ST & $\mathrm{R}$ & 4.23 & 17 & 0.501 & 0.1 & 0.2 & 52.55 & 1.38 & $\mathrm{~N}$ & (f) \\
\hline $\mathrm{J} 1058+0133$ & 23.04.07 & ST & $\mathrm{R}$ & 5.36 & 12 & 0.158 & 0.2 & 0.3 & 25.12 & 0.81 & $\mathrm{~N}$ & (f) \\
\hline $\mathrm{J} 1159+2914$ & 31.03 .12 & IGO & $\mathrm{R}$ & 5.93 & 18 & 0.134 & 0.6 & 0.7 & 34.89 & 0.53 & $\mathrm{~N}$ & (f) \\
\hline $\mathrm{J} 1159+2914$ & 01.04 .12 & IGO & $\mathrm{R}$ & 8.40 & 26 & 0.133 & 0.8 & 0.9 & 39.13 & 0.61 & $\mathrm{~N}$ & (f) \\
\hline $\mathrm{J} 1159+2914$ & 02.04 .12 & IGO & $\mathrm{R}$ & 7.22 & 20 & 0.144 & 1.5 & 2.9 & 69.58 & 1.59 & $\mathrm{~N}$ & (f) \\
\hline J1218-0119 & 11.03 .02 & ST & $\mathrm{R}$ & 6.16 & 34 & 0.049 & 1.3 & 3.0 & 225.39 & 2.39 & PV & (e) \\
\hline J1218-0119 & 13.03 .02 & ST & $\mathrm{R}$ & 8.48 & 24 & 0.074 & 0.2 & 0.5 & 158.12 & 1.62 & $\mathrm{~N}$ & (e) \\
\hline J1218-0119 & 15.03 .02 & ST & $\mathrm{R}$ & 3.91 & 11 & 0.077 & 0.2 & 0.3 & 29.68 & 0.59 & $\mathrm{~N}$ & (e) \\
\hline J1218-0119 & 16.03 .02 & ST & $\mathrm{R}$ & 8.20 & 22 & 0.072 & 0.2 & 0.3 & 121.40 & 1.52 & $\mathrm{~N}$ & (e) \\
\hline J1256-0547 & 26.01 .06 & ST & $\mathrm{R}$ & 4.75 & 21 & 0.596 & 0.1 & 0.2 & 65.87 & 1.38 & $\mathrm{~N}$ & (f) \\
\hline J1256-0547 & 28.02 .06 & ST & $\mathrm{R}$ & 6.51 & 42 & 0.601 & 0.1 & 0.2 & 91.54 & 0.81 & $\mathrm{~N}$ & (f) \\
\hline J1256-0547 & 20.04 .09 & ST & $\mathrm{R}$ & 5.46 & 22 & 0.601 & 0.2 & 0.3 & 43.51 & 0.75 & $\mathrm{~N}$ & (f) \\
\hline $\mathrm{J} 1310+3220$ & 26.04 .00 & ST & $\mathrm{R}$ & 5.99 & 18 & 0.971 & 1.0 & 1.8 & 48.79 & 1.34 & $\mathrm{~N}$ & (e) \\
\hline $\mathrm{J} 1310+3220$ & 17.03 .02 & ST & $\mathrm{R}$ & 8.37 & 21 & 1.050 & 0.8 & 0.6 & 17.49 & 0.27 & $\mathrm{~N}$ & (e) \\
\hline $\mathrm{J} 1310+3220$ & 24.04 .02 & ST & $\mathrm{R}$ & 5.81 & 14 & 1.045 & 0.5 & 0.3 & 7.70 & 0.17 & $\mathrm{~N}$ & (e) \\
\hline $\mathrm{J} 1310+3220$ & 02.05 .02 & ST & $\mathrm{R}$ & 5.08 & 15 & 0.031 & 0.5 & 0.4 & 8.61 & 0.21 & $\mathrm{~N}$ & (e) \\
\hline
\end{tabular}


Table 1 (cont'd)

\begin{tabular}{|c|c|c|c|c|c|c|c|c|c|c|c|c|}
\hline $\begin{array}{l}\text { AGN } \\
\text { name } \\
(1)\end{array}$ & $\begin{array}{l}\text { Obs. date } \\
\text { dd.mm.yy } \\
\text { (2) }\end{array}$ & $\begin{array}{l}\text { Tel.lI } \\
\text { used } \\
\text { (3) }\end{array}$ & $\begin{array}{l}\text { Filter. } \\
\text { used } \\
\text { (4) }\end{array}$ & $\begin{array}{l}\text { Dur. } \\
(\mathrm{hr}) \\
(5)\end{array}$ & $\begin{array}{l}N_{p} \\
\text { (6) }\end{array}$ & $\begin{array}{c}\Delta m_{s} \\
(\mathrm{mag}) \\
(7)\end{array}$ & 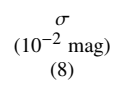 & $\begin{array}{c}\text { std dev. } \\
\left(10^{-2} \mathrm{mag}\right) \\
(9)\end{array}$ & $\begin{array}{l}\chi_{s}^{2} \\
(10)\end{array}$ & $\begin{array}{l}F_{s} \\
(11)\end{array}$ & $\begin{array}{c}\text { Status }^{\dagger} \\
\text { (12) }\end{array}$ & $\begin{array}{r}\operatorname{Ref}^{f} . \\
\text { (13) }\end{array}$ \\
\hline J1512-0906 & 14.06.05 & ST & $\mathrm{R}$ & 4.93 & 11 & 0.347 & 0.1 & 0.1 & 9.33 & 0.39 & $\mathrm{~N}$ & (f) \\
\hline J1512-0906 & 01.05 .09 & ST & $\mathrm{R}$ & 6.02 & 25 & 0.557 & 0.3 & 0.5 & 58.70 & 1.02 & $\mathrm{~N}$ & (f) \\
\hline J1512-0906 & 20.05 .09 & ST & $\mathrm{R}$ & 5.16 & 25 & 0.580 & 0.5 & 0.7 & 55.86 & 0.67 & $\mathrm{~N}$ & (f) \\
\hline $\mathrm{J} 2222-0457$ & 08.10 .10 & ST & $\mathrm{R}$ & 5.72 & 18 & 0.044 & 0.4 & 0.9 & 69.00 & 1.59 & $\mathrm{~N}$ & (g) \\
\hline \multicolumn{13}{|c|}{ TeV detected BL Lac objects (TeV-BLs)[13 sources; 54 DLCs] } \\
\hline $\mathrm{J} 0112+2244$ & 29.10 .05 & ST & $\mathrm{R}$ & 7.14 & 36 & 0.250 & 0.1 & 0.2 & 71.03 & 0.85 & $\mathrm{~N}$ & (h) \\
\hline $\mathrm{J} 0222+4302$ & 13.11 .99 & ST & $\mathrm{R}$ & 5.92 & 123 & 0.051 & 0.1 & 0.2 & 416.3 & 1.43 & PV & (i) \\
\hline $\mathrm{J} 0222+4302$ & 24.10 .00 & ST & $\mathrm{R}$ & 9.15 & 73 & 0.050 & 0.1 & 0.3 & 310.17 & 1.95 & $\mathrm{~V}$ & (i) \\
\hline $\mathrm{J} 0222+4302$ & 01.11 .00 & ST & $\mathrm{R}$ & 9.02 & 103 & 0.363 & 0.2 & 0.3 & 218.47 & 0.86 & $\mathrm{~N}$ & (i) \\
\hline $\mathrm{J} 0721+7120$ & 01.02 .05 & ST & $\mathrm{R}$ & 1.68 & 26 & 0.159 & 0.2 & 0.3 & 62.62 & 0.86 & $\mathrm{~N}$ & (g) \\
\hline J0738+1742 & 26.12.98 & ST & $\mathrm{R}$ & 7.79 & 49 & 0.122 & 0.4 & 0.6 & 89.48 & 0.75 & $\mathrm{~N}$ & (j) \\
\hline J0738+1742 & 30.12 .99 & ST & $\mathrm{R}$ & 7.44 & 64 & 0.066 & 0.4 & 0.5 & 96.90 & 0.64 & $\mathrm{~N}$ & (j) \\
\hline $\mathrm{J} 0738+1742$ & 25.12 .00 & ST & $\mathrm{R}$ & 6.01 & 42 & 0.061 & 0.4 & 0.5 & 69.02 & 0.69 & $\mathrm{~N}$ & (j) \\
\hline $\mathrm{J} 0738+1742$ & 24.12.01 & ST & $\mathrm{R}$ & 7.30 & 38 & 0.190 & 0.3 & 0.4 & 47.70 & 0.52 & $\mathrm{~N}$ & (j) \\
\hline J0738+1742 & 20.12 .03 & HCT & $\mathrm{R}$ & 6.00 & 38 & 0.818 & 0.2 & 0.3 & 71.02 & 0.80 & $\mathrm{~N}$ & (j) \\
\hline J0738+1742 & 10.12 .04 & ST & $\mathrm{R}$ & 6.23 & 30 & 0.512 & 0.2 & 0.3 & 98.67 & 1.17 & $\mathrm{~N}$ & (j) \\
\hline J0738+1742 & 23.12.04 & ST & $\mathrm{R}$ & 5.88 & 13 & 0.505 & 0.1 & 0.2 & 36.57 & 1.15 & $\mathrm{~N}$ & (j) \\
\hline $\mathrm{J} 0738+1742$ & 02.01 .05 & ST & $\mathrm{R}$ & 4.87 & 22 & 0.522 & 0.2 & 0.2 & 29.93 & 0.81 & $\mathrm{~N}$ & (j) \\
\hline J0738+1742 & 05.01 .05 & ST & $\mathrm{R}$ & 5.23 & 26 & 0.158 & 0.1 & 0.2 & 64.56 & 1.08 & $\mathrm{~N}$ & (j) \\
\hline J0738+1742 & 09.01.05 & ST & $\mathrm{R}$ & 7.13 & 30 & 0.152 & 0.1 & 0.2 & 64.47 & 0.90 & $\mathrm{~N}$ & (j) \\
\hline $\mathrm{J} 0738+1742$ & 09.11 .05 & ST & $\mathrm{R}$ & 4.27 & 19 & 0.624 & 0.1 & 0.2 & 48.34 & 1.13 & $\mathrm{~N}$ & (j) \\
\hline J0738+1742 & 16.11 .06 & ST & $\mathrm{R}$ & 4.97 & 21 & 0.033 & 0.2 & 0.3 & 64.94 & 1.10 & $\mathrm{~N}$ & (j) \\
\hline $\mathrm{J} 0738+1742$ & 29.11 .06 & ST & $\mathrm{R}$ & 6.49 & 28 & 0.516 & 0.2 & 0.3 & 66.83 & 1.00 & $\mathrm{~N}$ & (j) \\
\hline $\mathrm{J} 0738+1742$ & 17.12.06 & ST & $\mathrm{R}$ & 6.54 & 28 & 0.507 & 0.1 & 0.3 & 118.30 & 1.45 & $\mathrm{~N}$ & (j) \\
\hline J0738+1742 & 15.12.07 & ST & $\mathrm{R}$ & 7.05 & 29 & 0.162 & 0.1 & 0.2 & 89.88 & 1.35 & $\mathrm{~N}$ & (j) \\
\hline J0738+1742 & 16.12.07 & ST & $\mathrm{R}$ & 7.29 & 30 & 0.508 & 0.2 & 0.2 & 30.66 & 0.42 & $\mathrm{~N}$ & (j) \\
\hline $\mathrm{J} 0738+1742$ & 22.11 .08 & ST & $\mathrm{R}$ & 5.98 & 29 & 0.128 & 0.2 & 0.2 & 48.35 & 0.53 & $\mathrm{~N}$ & (j) \\
\hline J0738+1742 & 08.12.09 & ST & $\mathrm{R}$ & 6.94 & 31 & 0.128 & 0.3 & 0.5 & 80.87 & 0.91 & $\mathrm{~N}$ & (h) \\
\hline $\mathrm{J} 0738+1742$ & 05.01 .11 & ST & $\mathrm{R}$ & 6.80 & 32 & 0.330 & 0.3 & 0.4 & 43.17 & 0.51 & $\mathrm{~N}$ & (h) \\
\hline $\mathrm{J} 0738+1742$ & 29.11 .11 & ST & $\mathrm{R}$ & 6.11 & 29 & 0.499 & 0.2 & 0.3 & 34.25 & 0.51 & $\mathrm{~N}$ & (h) \\
\hline $\mathrm{J} 0809+3122$ & 28.12 .98 & ST & $\mathrm{R}$ & 7.29 & 36 & 0.844 & 0.3 & 0.6 & 153.04 & 1.69 & $\mathrm{~N}$ & (a) \\
\hline $\mathrm{J} 0809+5218$ & 04.02 .05 & HCT & $\mathrm{R}$ & 7.24 & 29 & 0.885 & 0.1 & 0.3 & 97.92 & 1.43 & $\mathrm{~N}$ & (g) \\
\hline $\mathrm{J} 0809+5218$ & 05.12.05 & HCT & $\mathrm{R}$ & 5.85 & 10 & 0.892 & 0.1 & 0.3 & 31.21 & 1.26 & $\mathrm{~N}$ & (g) \\
\hline $\mathrm{J} 0809+5218$ & 08.12.05 & HCT & $\mathrm{R}$ & 5.77 & 16 & 0.894 & 0.2 & 0.2 & 18.25 & 0.40 & $\mathrm{~N}$ & (g) \\
\hline $\mathrm{J} 0809+5218$ & 09.12 .05 & HCT & $\mathrm{R}$ & 5.46 & 14 & 0.892 & 0.2 & 0.2 & 17.38 & 0.56 & $\mathrm{~N}$ & (g) \\
\hline J0854+2006 & 29.12.98 & ST & $\mathrm{R}$ & 6.77 & 19 & 0.014 & 1.0 & 0.5 & 4.27 & 0.10 & $\mathrm{~N}$ & (i) \\
\hline J0854+2006 & 31.12 .99 & ST & $\mathrm{R}$ & 5.61 & 29 & 0.471 & 0.2 & 0.4 & 98.30 & 1.48 & $\mathrm{~N}$ & (i) \\
\hline J0854+2006 & 28.03 .00 & ST & $\mathrm{R}$ & 4.24 & 22 & 0.462 & 0.4 & 0.5 & 29.78 & 0.64 & $\mathrm{~N}$ & (i) \\
\hline J0854+2006 & 17.02 .01 & ST & $\mathrm{R}$ & 6.92 & 47 & 0.467 & 0.4 & 0.4 & 46.55 & 0.42 & $\mathrm{~N}$ & (i) \\
\hline J0854+2006 & 05.02.05 & HCT & $\mathrm{R}$ & 7.82 & 42 & 1.739 & 0.1 & 0.2 & 127.8 & 1.05 & $\mathrm{~N}$ & (g) \\
\hline J0854+2006 & 12.04 .05 & $\mathrm{ST}$ & $\mathrm{R}$ & 4.77 & 56 & 0.907 & 0.3 & 0.4 & 65.20 & 0.45 & $\mathrm{~N}$ & (g) \\
\hline $\mathrm{J} 1015+4926$ & 06.02 .10 & ST & $\mathrm{R}$ & 5.93 & 26 & 0.248 & 0.1 & 0.2 & 84.52 & 1.42 & $\mathrm{~N}$ & (g) \\
\hline $\mathrm{J} 1015+4926$ & 19.02 .10 & ST & $\mathrm{R}$ & 6.05 & 43 & 0.252 & 0.2 & 0.3 & 171.66 & 1.26 & $\mathrm{~N}$ & (g) \\
\hline $\mathrm{J} 1015+4926$ & 07.03.10 & ST & $\mathrm{R}$ & 5.50 & 36 & 0.180 & 0.2 & 0.4 & 132.23 & 1.14 & $\mathrm{~N}$ & (g) \\
\hline $\mathrm{J} 1221+2813$ & 19.03.04 & ST & $\mathrm{R}$ & 6.20 & 60 & 2.324 & 0.3 & 0.5 & 159.14 & 1.14 & $\mathrm{~N}$ & (g) \\
\hline $\mathrm{J} 1221+2813$ & 20.03 .04 & ST & $\mathrm{R}$ & 6.29 & 67 & 2.322 & 0.4 & 0.7 & 196.68 & 1.08 & $\mathrm{~N}$ & (g) \\
\hline $\mathrm{J} 1221+2813$ & 18.03.05 & ST & $\mathrm{R}$ & 4.18 & 28 & 1.301 & 0.2 & 0.5 & 116.81 & 2.22 & PV & (g) \\
\hline $\mathrm{J} 1221+2813$ & 05.04 .05 & ST & $\mathrm{R}$ & 7.28 & 41 & 1.280 & 0.2 & 0.4 & 170.26 & 1.75 & PV & (g) \\
\hline $\mathrm{J} 1221+3010$ & 08.03 .10 & IGO & $\mathrm{R}$ & 6.54 & 17 & 0.004 & 0.1 & 0.4 & 123.33 & 2.84 & PV & (g) \\
\hline $\mathrm{J} 1221+3010$ & 18.03 .10 & ST & $\mathrm{R}$ & 5.87 & 27 & 1.016 & 0.3 & 0.4 & 41.95 & 0.70 & $\mathrm{~N}$ & (g) \\
\hline $\mathrm{J} 1221+3010$ & 22.05 .10 & ST & $\mathrm{R}$ & 4.21 & 21 & 0.009 & 1.3 & 1.4 & 25.99 & 0.50 & $\mathrm{~N}$ & (g) \\
\hline $\mathrm{J} 1419+5423$ & 28.03.99 & ST & $\mathrm{R}$ & 5.65 & 33 & 0.142 & 0.3 & 0.5 & 68.98 & 0.82 & $\mathrm{~N}$ & (a) \\
\hline $\mathrm{J} 1428+4240$ & 21.04 .04 & HCT & $\mathrm{R}$ & 6.12 & 35 & 0.865 & 0.4 & 0.8 & 165.94 & 1.54 & $\mathrm{~N}$ & (g) \\
\hline $\mathrm{J} 1428+4240$ & 22.04 .09 & ST & $\mathrm{R}$ & 4.48 & 19 & 0.306 & 0.6 & 0.8 & 28.34 & 0.72 & $\mathrm{~N}$ & (g) \\
\hline
\end{tabular}


Table 1 (cont'd)

\begin{tabular}{|c|c|c|c|c|c|c|c|c|c|c|c|c|}
\hline $\begin{array}{l}\text { AGN } \\
\text { name } \\
(1)\end{array}$ & $\begin{array}{l}\text { Obs. date } \\
\text { dd.mm.yy } \\
\text { (2) }\end{array}$ & $\begin{array}{l}\text { Tel. }{ }^{\text {Il }} \\
\text { used } \\
\text { (3) }\end{array}$ & $\begin{array}{c}\text { Filter. } \\
\text { used } \\
\text { (4) }\end{array}$ & $\begin{array}{l}\text { Dur. } \\
\text { (hr) } \\
(5)\end{array}$ & $\begin{array}{l}N_{p} \\
\text { (6) }\end{array}$ & $\begin{array}{c}\Delta m_{s} \\
(\mathrm{mag}) \\
(7)\end{array}$ & $\begin{array}{c}\sigma \\
\left(10^{-2} \mathrm{mag}\right) \\
(8)\end{array}$ & $\begin{array}{c}\text { std dev. } \\
\left(10^{-2} \mathrm{mag}\right) \\
(9)\end{array}$ & $\begin{array}{l}\chi_{s}^{2} \\
(10)\end{array}$ & $\begin{array}{l}F_{s} \\
(11)\end{array}$ & $\begin{array}{l}\text { Status }{ }^{\dagger} \\
\text { (12) }\end{array}$ & $\begin{array}{r}\operatorname{Ref}^{f} \\
\text { (13) }\end{array}$ \\
\hline $\mathrm{J} 1428+4240$ & 29.04.09 & ST & $\mathrm{R}$ & 6.81 & 29 & 0.856 & 0.6 & 0.9 & 78.27 & 0.86 & $\mathrm{~N}$ & (g) \\
\hline $\mathrm{J} 1555+1111$ & 05.05 .99 & ST & $\mathrm{R}$ & 4.15 & 23 & 1.170 & 0.3 & 0.5 & 65.67 & 1.26 & $\mathrm{~N}$ & (a) \\
\hline $\mathrm{J} 1555+1111$ & 24.06 .09 & ST & $\mathrm{R}$ & 4.22 & 26 & 0.137 & 0.1 & 0.3 & 108.25 & 1.77 & $\mathrm{~N}$ & (g) \\
\hline $\mathrm{J} 1555+1111$ & 15.05 .10 & ST & $\mathrm{R}$ & 6.50 & 22 & 0.041 & 0.1 & 0.3 & 112.32 & 1.98 & $\mathrm{~N}$ & (g) \\
\hline $\mathrm{J} 1555+1111$ & 16.05 .10 & ST & $\mathrm{R}$ & 6.27 & 33 & 0.101 & 0.2 & 0.3 & 164.16 & 1.53 & $\mathrm{~N}$ & (g) \\
\hline
\end{tabular}

Columns :- (1) source name; (2) date of observation; (3) telescope used; (4) filter used; (5) duration of monitoring; (6) number of data points in the DLC; (7) mean apparent magnitude difference of the steady star-star pair; (8) quadratic mean of the IRAF errors for the steady star-star DLC; (9) standard deviation of the steady star-star DLC; (10) $\chi^{2}$-value for the star-star DLC; (10) $F$-value for the star-star DLC; (12) variability status for the star-star DLC; (13) reference for the INOV data.

II ST - Sampurnanand Telescope (ARIES); HCT - Himalayan Chandra Telescope (IIA); IGO - IUCAA Girawali Observatory; VBT - Vainu Bappu Telescope (IIA); GSO -

Gurushikhar telecsope (PRL).

$\dagger \mathrm{V}=$ Variable; $\mathrm{N}=$ Non-variable; $\mathrm{PV}=$ Probable Variable;

${ }^{£}$ References for the INOV data: (a) Stalin et al. (2005); (b) Goyal et al. (2007); (c) Stalin et al. (2004a); (d) Goyal et al. (2010); (e) Sagar et al. (2004); (f) Goyal et al. (2012); (g) Gopal-Krishna et al. (2011); (h) AGs unpublished data; (i) Stalin et al. (2004b); (j) Goyal et al. (2009).

\section{Acknowledgements}

AG would like to thank Dr. Santosh Joshi (ARIES) for carrring out optical observations on a few occasions. The authors are thankful to the anonymous referee for the critical and constructive suggestions.

\section{References}

Bachev R., Strigachev A., Semkov E., 2005, MNRAS, 358, 774

Bevington P. R., Robinson D. K., 2003, Data reduction and error analysis for the physical sciences

Box G. E. P., Cox D. R., 1964, Journal of the Royal Statistical Society, 26, 211

Box G. E. P., Hunter J. S., Hunter W. K., 2005, Statistics for experimenters : an introduction to design, data analysis, and model building

Carini M. T., Miller H. R., 1992, ApJ, 385, 146

Carini M. T., Miller H. R., Goodrich B. D., 1990, AJ, 100, 347 
Carini M. T., Miller H. R., Noble J. C., Goodrich B. D., 1992, AJ, 104, 15

Carini M. T., Miller H. R., Noble J. C., Sadun A. C., 1991, AJ, 101, 1196

Carini M. T., Noble J. C., Miller H. R., 1998, AJ, 116, 2667

Carini M. T., Noble J. C., Miller H. R., 2003, AJ, 125, 1811

Carini M. T., Noble J. C., Taylor R., Culler R., 2007, AJ, 133, 303

Cellone S. A., Romero G. E., Araudo A. T., 2007, MNRAS, 374, 357

de Diego J. A., 2010, AJ, 139, 1269

de Diego J. A., Dultzin-Hacyan D., Ramirez A., Benitez E., 1998, ApJ, 501, 69

Garcia A., Sodré L., Jablonski F. J., Terlevich R. J., 1999, MNRAS, 309, 803

Gaur H., Gupta A. C., Lachowicz P., Wiita P. J., 2010, ApJ, 718, 279

Gaur H. et al., 2012, MNRAS, 425, 3002

Gilliland R. L. et al., 1993, AJ, 106, 2441

Gopal-Krishna, Goyal A., Joshi S., Karthick C., Sagar R., Wiita P. J., Anupama G. C., Sahu D. K., 2011, MNRAS, 416, 101

Gopal-Krishna, Gupta A. C., Sagar R., Wiita P. J., Chaubey U. S., Stalin C. S., 2000, MNRAS, 314, 815

Gopal-Krishna, Sagar R., Wiita P. J., 1993a, MNRAS, 262, 963

Gopal-Krishna, Sagar R., Wiita P. J., 1995, MNRAS, 274, 701

Gopal-Krishna, Stalin C. S., Sagar R., Wiita P. J., 2003, ApJ, 586, L25

Gopal-Krishna, Wiita P. J., Altieri B., 1993b, A\&A, 271, 89

Goyal A., 2010, PhD thesis, Kumaun University, Uttarakhand, India

Goyal A. et al., 2009, MNRAS, 399, 1622

Goyal A., Gopal-Krishna, Joshi S., Sagar R., Wiita P. J., Anupama G. C., Sahu D. K., 2010, MNRAS, 401, 2622

Goyal A., Gopal-Krishna, Sagar R., Anupama G. C., Sahu D. K., 2007, Bulletin of the Astronomical Society of India, 35, 141

Goyal A., Gopal-Krishna, Wiita P. J., Anupama G. C., Sahu D. K., Sagar R., Joshi S., 2012, A\&A, 544, A37 
Gupta A. C. et al., 2008a, AJ, 136, 2359

Gupta A. C., Fan J. H., Bai J. M., Wagner S. J., 2008b, AJ, 135, 1384

Gupta A. C., Joshi U. C., 2005, A\&A, 440, 855

Gupta A. C. et al., 2012, MNRAS, 425, 1357

Gupta A. C., Yuan W., 2009, New Astronomy, 14, 88

Howell S. B., 1989, PASP, 101, 616

Howell S. B., Jacoby G. H., 1986, PASP, 98, 802

Howell S. B., VanOutryve C., Tonry J. L., Everett M. E., Schneider R., 2005, PASP, 117,1187

Jang M., Miller H. R., 1995, ApJ, 452, 582

Jang M., Miller H. R., 1997, AJ, 114, 565

Joshi R., Chand H., Gupta A. C., Wiita P. J., 2011, MNRAS, 412, 2717

Miller H. R., Carini M. T., Goodrich B. D., 1989, Nature, 337, 627

Miller H. R., Wiita P. J., 1991, Science, 254, 1238

Noble J. C., Carini M. T., Miller H. R., Goodrich B., 1997, AJ, 113, 1995

Ramírez A., de Diego J. A., Dultzin D., González-Pérez J.-N., 2009, AJ, 138, 991

Rani B., Gupta A. C., Joshi U. C., Ganesh S., Wiita P. J., 2010a, ApJ, 719, L153

Rani B., Gupta A. C., Joshi U. C., Ganesh S., Wiita P. J., 2011, MNRAS, 413, 2157

Rani B. et al., 2010b, MNRAS, 404, 1992

Romero G. E., Cellone S. A., Combi J. A., 1999, A\&AS, 135, 477

Romero G. E., Cellone S. A., Combi J. A., Andruchow I., 2002, A\&A, 390, 431

Sagar R., Gopal-Krishna, Wiita P. J., 1996, MNRAS, 281, 1267

Sagar R., Stalin C. S., Gopal-Krishna, Wiita P. J., 2004, MNRAS, 348, 176

Stalin C. S., 2003, PhD thesis, Kumaun University, Uttaranchal, India

Stalin C. S., Gopal-Krishna, Sagar R., Wiita P. J., 2004a, MNRAS, 350, 175

Stalin C. S., Gopal Krishna, Sagar R., Wiita P. J., 2004b, Journal of Astrophysics and Astronomy, 25, 1 
Stalin C. S., Gupta A. C., Gopal-Krishna, Wiita P. J., Sagar R., 2005, MNRAS, 356,607

Véron-Cetty M. P., Véron P., 2001, VizieR Online Data Catalog, 7224, 0

Villforth C., Koekemoer A. M., Grogin N. A., 2010, ApJ, 723, 737

Wagner S. J., Witzel A., 1995, ARA\&A, 33, 163

Wiita P. J., 2006, in Astronomical Society of the Pacific Conference Series, Vol. 350, Blazar Variability Workshop II: Entering the GLAST Era, Miller H. R., Marshall K., Webb J. R., Aller M. F., eds., p. 183 